
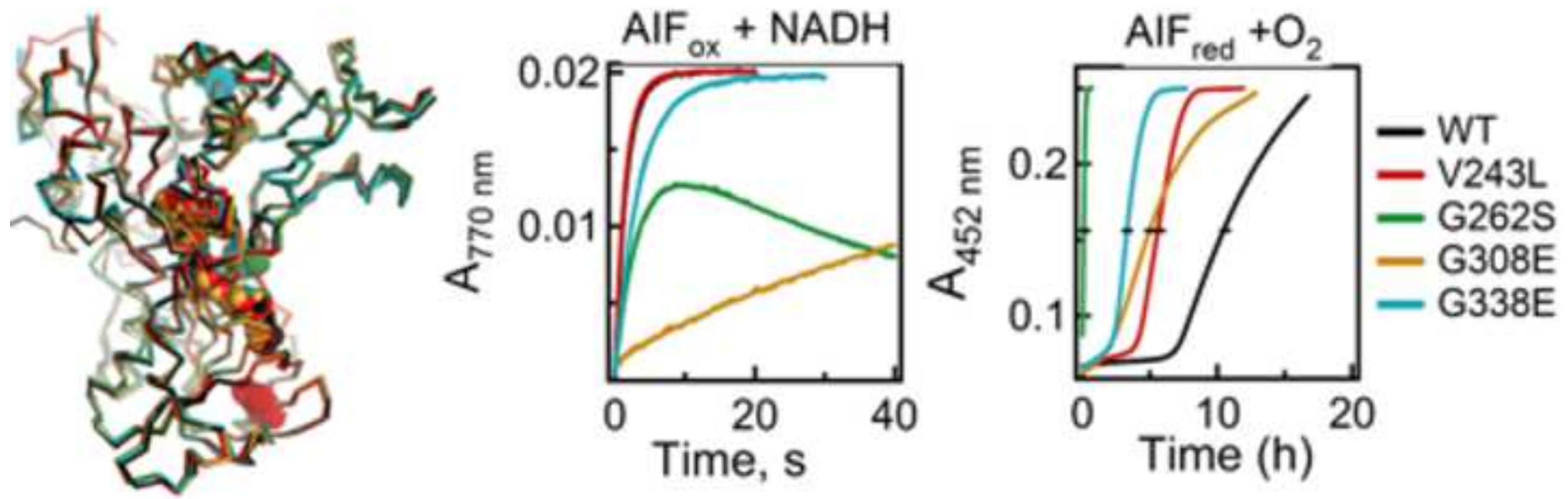

Mutational effect on the AIF structure/function: G308E > G262S>G338E >V243L WT 


\title{
Structure/function relations in AIFM1 variants associated with neurodegenerative disorders
}

\author{
Irina F. Sevrioukova* \\ Department of Molecular Biology and Biochemistry, University of California, Irvine, CA \\ 92697-3900, United States \\ ${ }^{*}$ Corresponding author:
}

University of California Irvine, Department of Molecular Biology and Biochemistry, 3205 McGaugh Hall, Irvine, California 92697-3900, USA.

Tel: (949) 824-1953, email: sevrioui@uci.edu 


\begin{abstract}
The X-linked AIFM1 gene encodes mitochondrial apoptosis inducing factor (AIF), an FAD-containing and NADH-specific oxidoreductase critically important for energy metabolism and execution of the caspase-independent cell death pathway. Several recently identified mutations in human AIFM1 lead to neurodegenerative disorders varying in severity and onset time. This study was undertaken to structurally and functionally characterize four pathologic variants of human AIF: V243L, G262S, G308E and G338E. A strong correlation between the mutational effects on the AIF function and clinical phenotype was observed only for the G308E aberration, drastingly damaging both the redox properties of AIF and mitochondrial respiration. In contrast, only minimal or mild changes were detected in the structure/function of AIF V243L and G338E, respectively, indicating that a marked decrease in their cellular expression likely triggers the disease. Alterations in the structure and redox activity of AIF G262S, on the other hand, were more severe than could be predicted based on the clinical phenotype. Together, the results of this and previous studies allow to conclude that phenotypic variability and severity of the AIFM1-related disorders depend on which AIF feature is predominantly affected (i.e., cellular production level, structure, redox or apoptogenic function) and to what extent. Only a drastic decrease in the expression level or/and redox activity of AIF tend to cause an early and severe neurodegeneration, whereas less pronounced changes in the AIF properties could lead to a broad range of slowly progressive neurological disorders.
\end{abstract}




\title{
Keywords
}

Apoptosis inducing factor, mitochondrial flavoprotein, pathologic mutation, NADH binding, crystal structure.

\author{
Abbreviations \\ AIF - apoptosis inducing factor; AIF $_{\text {red }}$ - 2-electron reduced form of AIF; CTC - charge- \\ transfer complex; DCIP - dichlorophenolindophenol; HT - hydride transfer; Mia40 - \\ mitochondrial intermembrane space import and assembly 40; OXPHOS - oxidative \\ phosphorylation.
}




\section{Introduction}

The human AIFM1 gene is located on the $\mathrm{X}$ chromosome and encodes apoptosis inducing factor (AIF), a mitochondrial FAD-containing protein. ${ }^{1}$ AIF is synthesized in the cytoplasm and, upon maturation and import to the mitochondrial intermembrane space, $\mathrm{N}$-terminally attaches to the inner mitochondrial membrane. After accepting two electrons from NADH in a form of a hydride ion, AIF undergoes dimerization and a conformational change, resulting in formation of an air-stable $\mathrm{FADH}^{\circ-} \mathrm{NAD}^{+}$charge transfer complex (CTC). ${ }^{2 ; 3 ; 4}$ AIF was initially suggested to function in vivo as a superoxide-producing $\mathrm{NADH}$ oxidase ${ }^{5}$ and, most recently, as a rotenone-sensitive NADH:ubiquinone oxidoreductase. ${ }^{6}$ Alternatively, based on the unique structural properties of the dimeric CTC form and its resistance to oxidation, AIF was proposed to operate as a $\mathrm{NAD}^{+}(\mathrm{H})$-sensor capable of regulating mitochondrial morphology and function through a specific redox activity or/and protein-protein interactions in the

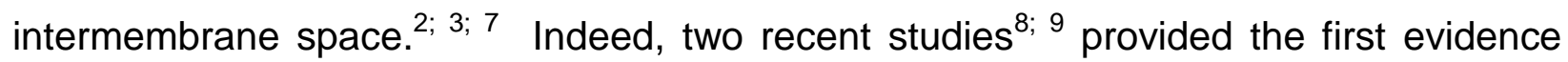
that AIF modulates the oxidative phosphorylation (OXPHOS) process through direct interaction and functional regulation of Mia40 (mitochondrial intermembrane space import and assembly 40, also known as $\mathrm{CHCHD4),} \mathrm{a} \mathrm{component} \mathrm{of} \mathrm{the} \mathrm{disulfide} \mathrm{relay}$ system playing a central role in the biogenesis and assembly of the respiratory chain complexes I and IV. ${ }^{10}$ In addition to the vital role in mitochondrial respiration, AIF is also a key player in a caspase-independent cell death pathway. ${ }^{1}$ Upon an apoptotic insult and proteolysis of the membrane tether, AIF translocates to the nucleus and, in cooperation with other proteins, promotes chromatin condensation and large-scale DNA degradation (reviewed in ${ }^{7}$ ). 
Studies on isolated cells and animal models showed that severe defects in the redox function or production of AIF could lead to mitochondrial fragmentation and respiratory defects (reviewed in ${ }^{11}$ ). To date, a number of pathologic mutations in human AIFM1 have been identified, ${ }^{12 ; 13 ; 14 ; 15 ; 16 ; 17 ; 18}$ among which only two, $\Delta R 201$ and E493V, were investigated on a molecular level. Deletion of Arg201 was found to perturb the protein folding and incorporation of FAD, affecting both the redox and apoptogenic properties of AIF and leading to a severe and early-onset encephalomyopathy. ${ }^{12 ; 13}$ In contrast, the E493V mutation caused only modest structural changes but enhanced the apoptogenic properties of AIF and, as a result, led to a slowly progressive neuronal damage. $^{13}$

The goal of this study was to investigate the impact of four other pathologic mutations, V243L, G262S, G308E and G338E, ${ }^{15 ; 16 ; 17 ; 18}$ on the structure and function of human AIF. Elucidation of how changes in the gene and encoded protein relate to the phenotype is one of the central problems in biomedical research, because this knowledge enables to distinguish genetic polymorphism from disease-causing mutations and find best approaches for the disease treatment and genetic manipulation. Data reported here not only provide deeper insights into the structure/function relationships in AIF but also clarify the pathologic mechanism of AIFM1 aberrations.

\section{Results}

\section{Expression and folding of the AIF mutants}

Production of AIF V243L, G262S and G338E in human cells was reported to be markedly reduced. ${ }^{15 ;} 18$ In E. coli, however, all mutants were expressed at high levels 
with fully incorporated FAD. Similar to the wild type (WT) AIF, all variants except G262S remained partially reduced during purification, forming an air-stable and blue-colored FADH ${ }^{\circ-N A D}{ }^{+}$CTC. In contrast, AIF G262S was oxidized immediately after separation from the bacterial cell lysate, which was the first indication of its perturbed redox properties. The oxidized proteins had absorbance and circular dichroism spectra nearly identical to those of WT (Fig. 1). This and similar flavin extinction coefficients (Table 1) indicate that none of the mutations affects protein folding and incorporation of FAD.

\section{Mutational effects on the equilibrium NADH binding, NADH-to-FAD hydride transfer kinetics, CTC stability and redox activities of AIF}

Equilibrium titrations with NADH - Similar to WT, none of the investigated mutants stabilized the 1-electron reduced FAD semiquinone during anaerobic titrations (Fig. 2). AIF V243L and G338E required only a slight NADH excess to convert to the 2-electron reduced CTC form (Fig. 2B,C). On the contrary, a large excess of the reductant was needed to fully reduce AIF G262S (Fig. 2D), which reacted with NADH considerably slower and produced CTC with a 2 -fold weaker long-wavelength absorption $\left(\varepsilon^{\mathrm{CTC}}{ }_{780 \mathrm{~nm}}\right.$ of 1.6 vs. $2.9 \mathrm{mM}^{-1} \mathrm{~cm}^{-1}$ for WT; Fig. 1A). Moreover, the spectral dissociation constant estimated for the AIF-G262S-NADH complex $\left(\mathrm{K}_{\mathrm{s}}^{\mathrm{NADH}}\right.$, a measure of the binding affinity) was almost 300-fold higher relative to that for WT (Table 1). One contributing factor for such a drastic change could be a $36 \mathrm{mV}$ decrease in the redox potential of AIF G262S ( $E_{\mathrm{m}, 8}$ of -389 vs. $-353 \mathrm{mV}$ for WT and $-350 \mathrm{mV}$ for $\mathrm{NADH}$ ), lowering the driving force for the NADH-to-FAD hydride transfer, due to which higher NADH concentrations are required to shift equilibrium toward the fully reduced FAD. The G308E mutation had no 
effect on the AIF redox potential but reduction of this variant with $\mathrm{NADH}$ proceeded extremely slowly. Due to time limitations, $\mathrm{K}_{\mathrm{s}}{ }^{\mathrm{NADH}}$ for AIF G308E was derived from a composite titration plot (Fig. 2E), where each data point was obtained in a separate experiment conducted at a fixed NADH concentration. This value was found to be $70-$ fold higher than the respective parameter for WT AIF (Table 1).

NADH-to-FAD hydride transfer kinetics - Kinetics of AIF reduction with NADH was analyzed by stopped flow spectrophotometry at two wavelengths, 452 and $770 \mathrm{~nm}$, to follow the hydride transfer $(\mathrm{HT})$ to $\mathrm{FAD}$ and formation of the $\mathrm{FADH}^{\circ-}-\mathrm{NAD}^{+} \mathrm{CTC}$, respectively. Kinetic traces recorded for each variant at saturating $\mathrm{NADH}$, as well as parameters derived from the $k_{\text {obs }} v s$. [NADH] plots, are shown in Figure 3 and Table 1. The V243L mutation had no effect on the NADH-to-FAD hydride transfer. Reduction of AIF G338E proceeded somewhat slower than WT, with the limiting rate constant

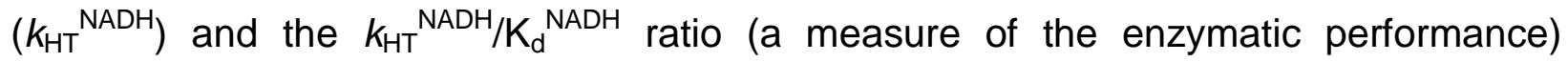
decreased by 2-3-fold (Table 1). Upon reaction of NADH with AIF G262S, an initial rise in the $770 \mathrm{~nm}$ absorbance was followed by a gradual decrease (Fig. 3B). Since the flavin remained fully reduced at the end of measurements (Fig. $3 \mathrm{~A}$ ), the $770 \mathrm{~nm}$ absorbance decay was not due to the reverse hydride transfer to $\mathrm{NAD}^{+}$. Taking into account a distinct optical spectrum of the CTC produced by AIF G262S (Fig. 1A), it can be concluded that the initial $\mathrm{FADH}^{\circ}-\mathrm{NAD}^{+}$complex gradually isomerizes into another form that absorbs weaker in the long-wavelength region. The most drastic effect on the reduction kinetics, however, was found for the G308E mutation (Fig. 3A,B and D), which decreased the $K_{H T}{ }^{N A D H} / K_{d}{ }^{N A D H}$ value by $>120$-fold (Table 1). 
NADH and CTC oxidation kinetics - The NADH oxidase activity of AIF V243L, G308E and G338E was very low and close to that of WT $\left(k_{0 x}{ }^{\mathrm{NADH}}\right.$ of $0.8-5.8$ vs. $1.6 \mathrm{~min}^{-1}$, respectively), whereas the G262S variant transferred electrons from NADH to oxygen

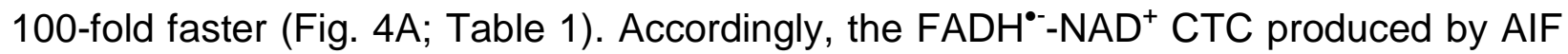
G262S had the shortest half-life under air atmosphere: $t^{C T C}{ }_{1 / 2}$ of 6 min $v s .11 \mathrm{~h}$ for WT (Fig. 4B). Other mutations also affected the rate of CTC oxidation but to a considerably lesser extent (Table 1).

Redox activities - Under physiological conditions, WT AIF and the V243L and G338E mutants had barely detectable electron transferase activities toward 2- and 1-electron acceptors, dichlorophenolindophenol (DCIP) and cytochrome $c$, respectively (Table 1). The $k_{\text {cat }} / K_{M}{ }^{N A D H}$ values for AIF G262S were several-fold higher, presumably due to instability and faster oxidation of CTC (Fig. 4B). In contrast, no DCIP or cytochrome $c$ reductase activity could be detected for the G308E mutant, possibly because of slow hydride transfer to FAD.

Summing up, the equilibrium binding and kinetic data indicate that the mutational effect on the redox function of AIF decreases in the order: G308E > G262S > G338G > $\mathrm{V} 243 \mathrm{~L} \approx \mathrm{WT}$. All mutations destabilize CTC to a various extent, with V243L having the smallest impact. The G338E aberration has no significant influence on the equilibrium binding of $\mathrm{NADH}$ and moderately affects the hydride transfer kinetics and redox activities of AIF. The G262S and G308E substitutions, on the other hand, altered all investigated parameters: the binding affinity of AIF for NADH, the FAD reduction and CTC formation/oxidation kinetics, and steady-state redox activities. 


\section{Mutational effect on the redox-dependent conformational reorganization in AIF and interaction with DNA}

Upon reduction with NADH, AIF undergoes dimerization and structural reorganization involving the regulatory peptide (residues $510-560$ ). ${ }^{3 ; 4}$ The redox-linked conformational changes are important because they could affect association of AIF with protein partners ${ }^{8}$ and DNA. ${ }^{2}$ It was investigated, therefore, how mutations affect the ability of AIF to undergo NADH-dependent conformational changes and bind DNA.

Redox-linked monomer-dimer transition - The NADH-reduced forms of AIF V243L, G308E and G338E are resistant to oxidation, owing to which their oligomeric state can be analyzed by gel filtration chromatography under aerobic conditions. As seen from Figure $5 \mathrm{~A}$, all three variants dimerized upon reduction with $\mathrm{NADH}$. Since the CTC form produced by AIF G262S is short-lived (Fig. 4B), its oligomeric state was determined under anaerobic conditions by chemical crosslinking with $\mathrm{BS}^{3}$, a primary-amine-reactive agent conjugating the $\mathrm{NADH}$-reduced dimers but not oxidized monomers of $\mathrm{AlF}^{2}{ }^{2}$ Electrophoretic detection of a $\mathrm{BS}^{3} / \mathrm{NADH}$-dependent $120 \mathrm{kDa}$ band, corresponding to the AIF dimer (Fig. 5B), confirmed the ability of the G262S mutant to undergo redoxlinked dimerization.

Limited proteolysis - The 510-560 regulatory peptide contains a trypsin site fully accessible only in the NADH-reduced form and, therefore, the redox-induced reorganization in AIF can be monitored by analyzing trypsin digest patterns. ${ }^{2}$ Limited proteolysis of the oxidized and NADH-reduced variants resulted in patterns nearly 
identical to those observed for WT AIF (Fig. 5C). This suggests that neither mutation affects spatial organization and redox-dependent rearrangement of the regulatory peptide.

Interaction with DNA - Association of AIF with DNA is a critical step in the caspaseindependent apoptotic pathway ${ }^{19}$ that requires cooperation with other proteins. ${ }^{7}$ In vitro, isolated AIF binds weakly and preferably to the large fragments of linearized double stranded DNA, ${ }^{2}$ which can be evaluated using a gel retardation assay. Unlike the $\triangle \mathrm{R} 201$ and E493V aberrations, markedly promoting the AIF-DNA complex formation, ${ }^{12}$ ${ }^{13}$ the electrophoretic mobility of DNA was virtually unchanged when WT AIF was substituted by the V243L, G262S, G308E or G338E mutants (Fig. 5D). It can be concluded, therefore, that none of the investigated mutations significantly affects the DNA-binding ability of AIF and its molecular properties, in general.

\section{Mutational effects on the AIF structure}

The high resolution X-ray structures were determined for all four variants in the ligandfree form (Table 2). Similar to WT,${ }^{19}$ AIF G308E was crystallized in the $\mathrm{P} 2{ }_{1}$ space group with one molecule per asymmetric unit. The V243L, G262S and G338E mutants produced crystals in the $\mathrm{P} 2{ }_{1} 2_{1} 2_{1}$ space group with two molecules in the unit cell ( $\mathrm{A}$ and B), differing only in the conformation of a few surface peptides forming contacts in the crystal lattice. The better defined molecules A were used for comparative analysis discussed below. Structural superposition with the ligand-free WT model (PDB ID 4BV6; Fig. 6A) shows that neither mutation alters the AIF fold. The plot of r.m.s. deviation 
between the main chain atoms of WT AIF and each mutant is shown in the Supplemental Data Figure 1S. The regulatory peptide is almost fully disordered in AIF V243L and G262S but partially visible in the AIF G308E and G338E structures.

\section{Structure of AIF V243L}

Val243 is located $8 \AA$ away from the nearest atom of the adenylate moiety of FAD (Fig. $6 \mathrm{~A})$ and forms hydrophobic contacts with the $\beta$-sheet residues comprising the core of the Rossmann fold. The $1.90 \AA$ crystal structure indicates that only local and small structural adjustments are needed to accommodate Leu243 (Fig. 6B). Moreover, reorientation of Leu135 and positional shifts in other neighboring residues strengthen rather than weaken hydrophobic interactions at this site.

\section{Structure of AIF G308E}

Gly308 lines the wall of the NADH-binding channel and is part of the adenosine ribose docking site (Fig. 6A). In the $1.40 \AA$ crystal structure, Glu308 is well ordered and forms hydrogen bonds with the main chain amide nitrogen, two water molecules, and the Lys342 side chain (Fig. 6C). Besides the Lys342 reorientation, a different conformer of Glu336 is needed to accommodate Glu308. Importantly, according to the structure of reduced, NAD+-bound WT AIF (AIF red $-\mathrm{NAD}^{+}$; PDB ID 4BUR), ${ }^{4}$ Glu336 stabilizes the protein-ligand complex by establishing a hydrogen bond with the adenosine ribose. Lys342, on the other hand, is $\mathrm{H}$-bonded to the $\mathrm{NAD}^{+}$pyrophosphate group only in one out of four independent molecules present in the asymmetric unit (Fig. 7A). This conformational heterogeneity could arise from the low $(3.0 \AA)$ resolution of the 4BUR 
structure, disallowing to accurately define the Lys342 side chains. In the analogous 2.24 $\AA$ structure of the murine isoform (PDB ID $3 G D 4 ;{ }^{3} 92 \%$ identical to human AIF), the homologous Lys341 residue forms a strong $\mathrm{H}$-bond with the $\mathrm{NAD}^{+}$pyrophosphate in both molecules present in the unit cell (2.6-2.8 $\AA$ bond length), which strengthens the protein-ligand interaction. Moreover, the G307E mutation (equivalent to G308E in human AIF) has a similar effect on the redox function. ${ }^{20}$ It is possible, therefore, that Glu308 decreases the AIF affinity for NADH and kinetics of the FAD reduction not only by sterically blocking the $\mathrm{NAD}^{+}(\mathrm{H})$ access channel but also by reorienting and disengaging Glu336 and Lys342 from the interactions stabilizing the $\mathrm{AlF}_{\text {red }}-\mathrm{NAD}^{+}$ complex (Fig. 7A)

\section{Structure of AIF G338E}

Gly338 also comprises part of the NADH-binding domain (Fig. 6A) but is situated on the outer surface and further away $(\sim 8 \AA)$ from the adenylate ribose moiety. The $1.75 \AA$ crystal structure demonstrates that only small positional shifts in the neighboring residues take place upon incorporation of the bulkier and acidic Glu338 (Fig. 6D). Ser349 reorients to allow H-bonding with the Glu338 carboxyl group, which also establishes two water-mediated contacts with the Lys337 and Asn350 main and side chain atoms, respectively. Introduction of the negatively-charged Glu338 and rearrangement of the aforementioned residues alter electrostatic potential at the surface near the entrance to the $\mathrm{NAD}^{+}(\mathrm{H})$ binding channel, which might affect the ligand docking and formation of an initial AIF-NADH complex (e.g., through repulsion with the negatively-charged pyrophosphate group). If true, this could explain why the G338E 
mutation perturbs the hydride transfer kinetics more notably than the equilibrium binding of NADH.

Glu338 was also suggested to cause pathology ${ }^{18}$ because, in the CTC form, the surrounding surface binds the Gln556-containing fragment of the regulatory peptide, possibly assisting the redox-linked conformational switch. Superposition of the WT $\mathrm{AlF}_{\text {red }}-\mathrm{NAD}^{+}$and $\mathrm{G} 338 \mathrm{E}$ structures (Fig. 7B) shows that residue 338 closely approaches the Glu346-containing $\alpha$-helix adjacent to the regulatory peptide. It should be noted that Glu346 and the neighboring Lys337 are exposed into a solvent channel in the G338E mutant but engaged in electrostatic interactions with the symmetry related molecule in $\mathrm{AIF}_{\text {red }}-\mathrm{NAD}^{+}$. The helix displacement in the latter structure, therefore, could be a crystallographic artifact. Since it is unclear how this surface would look without packing constraints, the impact of the G338E substitution on the regulatory peptide folding cannot be accurately deduced. Nonetheless, as seen from Figure 7B, the mutational effect could be minimized or even eliminated if Glu346 adopts a different rotamer. This possibility and similarity of the trypsin digest patterns (Fig. 5C) suggest that the redox switch in the regulatory peptide should not be seriously affected by the G338E substitution. To fully rule out this possibility, though, determination of the NADH-reduced structure of AIF G338E would be required.

\section{Structure of AIF G262S}

Gly262 lies on the border of the FAD- and NAD-binding domains and in the vicinity of the flavin pyrophosphate group (Fig. 6A). When the entire structures of the WT and G262S AIF are superimposed, there is a notable $(\sim 1.0 \AA)$ shift of the isoalloxazine ring, 
the redox moiety of FAD (Fig. 8A). This could arise from a slightly different inter-domain orientation caused by different crystal packing because, when only the active sites/FADdomains of the WT and G262S AIF are aligned, the isoalloxazine displacement becomes considerably smaller ( 0.3 Å; Fig. 8B). To avoid bias and more accurately pinpoint conformational changes, AIF G262S was compared to the V243L mutant, which crystallizes in the same space group and is structurally most similar. As mentioned earlier, the area near the catalytic center is not affected by the V243L substitution. Alignment of the two mutant structures showed that, indeed, the G262S mutation slightly distorts the flavin mononucleotide portion of FAD (by $\sim 0.2 \AA$; Fig. $8 \mathrm{~B}, \mathrm{C})$. This may result from the Ser262-triggered rearrangement in the neighboring Arg285, Asp438, Arg451 and Glu453, leading to formation of an extensive H-bonding network that involves preexisting and newly recruited water molecules (Fig. 8D). Arg451 and Glu453 are part of the 451-455 peptide stretching along the ribitol and isoalloxazine moieties and, hence, even small positional changes in these residues could impose steric constraints leading to the FAD distortion. Most importantly, introduction of a bulkier Ser at position 262 forces the nearby Leu400 residue to shift and adopt another rotamer, with the side chain moving toward the $\mathrm{NAD}^{+}(\mathrm{H})$-binding channel by $\sim 1.5 \AA$ (Fig. 8E). When $\mathrm{NAD}^{+}$is modeled into the channel based on the 4BUR structure, the distance between Leu400 and the nicotinamide ribose is only $2.9 \AA$.

The outlined structural rearrangement could explain changes in the redox properties of AIF G262S. Although the $\operatorname{NAD}^{+}(\mathrm{H})$-binding channel remains passable upon the Leu400 shift, the bottleneck region, where the ribose/nicotinamide moiety bends to align with the FAD isoalloxazine, is narrowed by $1.3 \AA$ (Fig. 8F). A decrease in 
the maneuvering space and formation of the Ser262-mediated H-bond cluster nearby could lower conformational flexibility needed for adjustments during association of $\operatorname{NAD}^{+}(H)$. A suboptimal ligand orientation, in turn, could weaken/disfavor $\pi-\pi$ stacking interactions between the isoalloxazine and nicotinamide rings, a prerequisite for the CTC formation. Charge redistribution, increased solvation near the catalytic center and conformational distortion of FAD, on the other hand, could affect the redox potential. Collectively, these changes lead to destabilization and faster oxidation of CTC (Figs. 3B and 4B), and enhance the redox activity of AIF (Table 1). The absorbance spectrum of the oxidized G262S mutant was not altered (Fig. 1A) because the hydrogen bonding interactions with the $\mathrm{C} 2=\mathrm{O}$ and $\mathrm{C} 4=\mathrm{O}$ carbonyl groups and $\mathrm{N} 5$ atom of the isoalloxazine chromophore, known to affect the location and intensity of the absorption peaks, were preserved.

Taken together, the X-ray data indicate that the mutational effect on the AIF structure decreases in the order: G262S > G308E > G338G > V243L $\approx$ WT. The V243L substitution causes only minor and local readjustments in the core of the FAD-binding domain, far away from the redox center. The G308E and G338E mutations alter the surface inside and outside of the NADH-binding channel, respectively, thereby hindering the equilibrium binding of $\mathrm{NADH}$ and the hydride transfer kinetics to different extents. The G262S replacement triggers the most notable structural changes which could affect both the flavin redox potential and formation/stability of CTC. Overall, however, the G308E mutation is more deleterious than G262S because it has the largest impact on the AIF redox function. 


\section{Discussion}

Since discovery two decades ago, ${ }^{1 ; 21 ; 22}$ AIF has emerged as a major player not only in the execution of the programmed cell death but also in the regulation of mitochondrial morphology and energy metabolism. ${ }^{7 ; 11 ; 23 ; 24}$ For a long time, however, it remained unknown what phenotypic changes would be caused by aberrations in human AIF. Recent identification of several pathologic mutations in the human AIFM1 gene ${ }^{12 ; 13 ; 14 ;}$ 15; 16; $17 ; 18$ and in vitro characterization of six variants conducted in this and previous studies $^{12 ; 13}$ provide an opportunity to analyze how changes on a molecular level relate to the clinical phenotype (summarized in Table 3).

\section{AlFM1 mutations with a strong genotype/phenotype correlation}

G308E - Among known AIFM1 aberrations, the G308E substitution is the most pathologic because it leads to a prenatal OXPHOS-related encephalopathy, muscle atrophy and early death. ${ }^{17}$ Here we showed that introduction of Glu in a highly conserved GXG XXG motif has no influence on the expression, folding and redox potential of AIF but decreases its affinity for NADH and the hydride transfer efficiency by two orders of magnitude, as evident from the $\mathrm{K}_{\mathrm{s}}$ and $\mathrm{K}_{H} \mathrm{NADH}^{\mathrm{Na}} / \mathrm{K}_{d}{ }^{\mathrm{NADH}}$ values, respectively (Table 1). As a result, the G308E mutant cannot produce sufficient amounts of CTC and effectively catalyze redox reactions. According to the crystal structure (Figs. 6C and 7A), Glu308 exerts its damaging effect by sterically blocking the cofactor access channel and, possibly, by disengaging Lys342 and Glu336 from the interactions stabilizing the $\mathrm{AIF}_{\text {red }}-\mathrm{NAD}^{+}$complex. 
A structurally distinct CTC dimer was proposed to mediate protein-protein interactions important for the mitochondrial function. ${ }^{3 ;} 7$ At the moment, only Mia40, a small redox protein critically important for the biogenesis of the respiratory chain, ${ }^{10}$ was identified as the AIF partner in the mitochondrial intermembrane space. ${ }^{8 ;} 9$ Through physical interaction and translational regulation, AIF controls expression, mitochondrial import and conformational stability of Mia40 and, as a result, indirectly assists the assembly and functioning of the respiratory complexes I and IV. ${ }^{8 ;} 9$ No mechanistic investigations of the AIF-Mia40 interaction have been conducted yet. It was reported though that only mature $(\Delta 1-54)$ AIF binds Mia40 in vivo, ${ }^{8 ; 9}$ and that their complex formation is promoted by $\mathrm{NAD}(\mathrm{P}) \mathrm{H}$ and markedly inhibited by the G308E but not by the E493V mutation. ${ }^{4}$ Thus, diminished association with Mia40 due to a drastic decline in the efficiency of the NADH-to-AIF electron transfer appears to be the major factor leading to severe OXPHOS defects and rapidly progressive encephalomyopathy in patients harboring the G308E mutation ${ }^{17}$ (Table 3).

$\Delta R 201$ - Structural and functional alterations caused by the $\Delta \mathrm{R} 201$ mutation also correlate well with the clinical phenotype..$^{12 ; 13}$ In the oxidized and NADH-reduced forms of AIF, Arg201 is involved in the hydrogen bonding network that assists folding of the $\beta$ hairpin (residues 191-203) and the regulatory peptide. ${ }^{4 ;} 19$ Deletion of Arg201 leads to conformational instability, weaker FAD binding, and drastic changes in the redox and DNA-binding properties of AIF. ${ }^{12}$ In human cells, the mutation has no effect on the AIF expression but leads to enhanced caspase-independent cell death, tissue-specific mitochondrial DNA depletion, and OXPHOS failure due to a $35-90 \%$ reduction of the 
respiratory complex III and IV activities (Table 3). As a result, both children carrying the $\Delta$ R201 mutation developed severely progressive mitochondrial encephalomyopathy and one of them died under the age of $2 .^{12}$

E493V - In contrast, replacement of Glu493 with Val does not perturb mitochondrial energy metabolism and leads to a slowly progressive, childhood-onset disorder (Cowchock syndrome) with axonal neuropathy, deafness and cognitive impairment. ${ }^{13}$ Glu493 assists folding of the regulatory peptide in oxidized AIF and is part of the peripheral non-catalytic NADH-binding site in the reduced form of the flavoprotein. ${ }^{4}$ The E493V mutation has no effect on the AIF folding, cellular expression or OXPHOS activity, and only mildly perturbs the AIF-NADH binding process and stability of CTC. ${ }^{13}$ The main difference with WT AIF is the higher affinity of the E493V variant for binding to DNA and its ability to promote caspase-independent cell death, which could be the major cause of the disease. Overall, mild changes in the AIF structure/function and unaffected energy metabolism correlate well with the slowly progressive axonal neuropathy syndrome (Table 3).

\section{AIFM1 mutations with a weak genotype-phenotype correlation}

G338E - Gly338 is a surface residue, whose replacement with Glu only modestly perturbs the structure and redox function of AIF and has no effect on the AIF-DNA interaction (Figs. 5D, 6D and 7B; Table 1). Although in vivo expression of AIF G338E was reduced to almost trace levels, there were no serious defects in the OXPHOS system except a $25-40 \%$ decline in the complex IV activity ${ }^{18}$ (Table 3). The latter finding 
does not correlate with the clinical phenotype of severe and early-onset encephalopathy, muscular atrophy and motor axonal neuropathy observed in two infants harboring the G338E mutation. ${ }^{18}$ Albeit the low availability of AIF G338E could certainly trigger the disease, the mutational effect on cellular physiology appears to be more complicated and, therefore, needs to be thoroughly clarified.

V243L - This AIFM1 mutation was identified in a child with progressive muscular atrophy, ataxia and hearing loss. ${ }^{15}$ The only biochemical abnormality reported was a $40 \%$ decline in the respiratory complex I content and decreased AIF expression in the muscle cells (Table 3). Based on the latter observation, the V243L replacement was suggested to be damaging for the AIF structure. ${ }^{15}$ This study ruled out this possibility and showed that the mutation has virtually no influence on the folding, redox and DNAbinding properties of AIF (Figs. 5D and 6A,B; Table 1). Given that residue 243 is buried, its potential involvement in the interaction with Mia40 and other partners can be excluded as well. Again, the diminished cellular availability rather than structure/function changes in AIF V243L is the likely pathologic cause.

G262S - The G262S substitution represents an opposite case, when changes in the AIF protein are more severe than can be predicted based on the phenotype (Table 3). Introduction of a polar and bulkier Ser residue at position 262 triggers significant structural perturbations in the active site (Fig. 8), leading to a marked decrease in the affinity and stability of the $\mathrm{AlF}_{\text {red }}-\mathrm{NAD}^{+}$complex (Figs. 2D, 3B, 4B and Table 1). Compared to WT, the NADH-reduced form of AIF G262S decays 100 -fold faster and, 
hence, its in vivo availability and production of the functionally important complex with Mia40 should decline accordingly. Moreover, the negative effect on mitochondrial respiration could be further exacerbated by the diminished cellular expression of AIF G262S. ${ }^{16}$ The phenotypic changes, however, were not as severe as the in vitro data and in vivo expression profile predict. The patient carrying the G262S mutation had a $40-80 \%$ deficiency in the mitochondrial complex I and IV activities but was normal until one year of age and, during childhood, developed axonal neurophathy, hearing loss and cognitive impairment. ${ }^{16} \mathrm{He}$ was still alive at 39 although wheelchair-bound.

Differences in the extent and severity of the enzymatic and phenotypic changes imply that either the oxidized AIF monomers bind Mia40 fairly well or there is a compensatory mechanism minimizing the mutational impact on the OXPHOS system. It is possible, for instance, that binding of Mia40 or/and other mitochondrial partners could slow down the CTC decay by limiting access of oxygen and other natural electron acceptors, such as ubiquinone,$^{6}$ to the redox center. Investigation of the AIF-Mia40 interaction on a molecular level could clarify this matter and help to more accurately predict pathogenicity of the missense mutations in AIFM1. At the moment, only two out of four prediction servers could correctly rank the G262S mutation as disease-causing and deleterious. ${ }^{16}$

It is important to investigate also why expression of AIF V243L, G262S and G338E is downregulated in human cells ${ }^{15}, 16 ; 18$ because this could be the leading pathologic cause. Only intracellular protein levels were measured for each mutant and, hence, it is unknown at what stage the AIF production is affected: mRNA synthesis, translation or protein degradation. Since all three variants were properly folded and 
robustly produced in E. coli, translational termination due to protein misfolding is unlikely to be the major control point. Currently, little is known about transcriptional regulation and proteosomal degradation of AIF. Among four transcriptional regulators of AIFM1 identified so far, ${ }^{25 ; 26 ; 27 ; 28}$ only hepatocyte growth factor and Bcl-2 19 kDa interacting protein (BNPI3) act as suppressors of AIF expression. Elucidation of whether or not these factors are upregulated in the mutant cells could help identify networks altered in the AIFM1-associated disorders and improve therapeutic strategies.

In summary, this study was undertaken to investigate structural and functional impacts of the V243L, G262S, G308E and G338E mutations on human AIF, and how changes in the protein relate to the clinical phenotype. Determination of the high resolution X-ray structures and biochemical characterization of the variants helped better understand structure/function relationships in AIF, clarify molecular mechanisms underlying clinical symptoms, and carry out comparative analysis with other pathologic AIFM1 mutants. Based on our and previously reported data, it was possible to conclude that phenotypic severity in the AIFM1-related disorders depends on the AIF property predominantly affected and the extent of the damage. An early and severe mitochondrial disease is likely to develop if the expression level or/and redox activity of AIF are drastically decreased, whereas less pronounced perturbations in the production, structure/function or/and DNA binding ability of AIF could lead to a wide range of slowly progressive neurological disorders. To fully understand the AIF function and regulation and improve performance of the mutation pathogenicity prediction methods, however, identification and comparative analysis of more genetic aberrations in AIFM1 is needed. 


\section{Materials and Methods}

Protein mutagenesis, expression and purification - Mutations were introduced to the pKK233-3 expression plasmid (Amersham) for the $\Delta 1-102$ catalytic domain of human AIF with a cleavable C-terminal 6-His affinity tag using a Stratagene QuikChange kit (Agilent). Protein expression, purification and tag removal was conducted as previously described for murine AIF. ${ }^{2}$ Briefly, Escherichia coli BL21(DE3) cells, transformed with the AIF expression plasmid, were grown in TB media and harvested one day after induction with $60 \mu \mathrm{M}$ isopropyl $\beta$-D-1-thiogalactopyranoside. Cells were disrupted in 50 $\mathrm{mM}$ phosphate buffer, $\mathrm{pH} 8.0$, supplemented with $0.1 \mathrm{mM}$ phenylmethylsulfonyl fluoride, $0.1 \mathrm{mM}$ leupeptin and $0.1 \mathrm{mM}$ calpeptin (buffer A) using a microfluodizer (Microfluidics, USA). The supernatant was loaded on the Ni-affinity resin in buffer A with $20 \mathrm{mM}$ imidazole. After extensive washing with the loading buffer, AIF was eluted with buffer A containing $80 \mathrm{mM}$ imidazole. The purest fractions were combined, concentrated and treated with thrombin (2 Units/mg; Sigma) overnight at room temperature. The cleaved affinity tag and undigested protein were removed by passing the mixture through the $\mathrm{Ni}$ affinity column equilibrated in buffer $\mathrm{A}$ with $5 \mathrm{mM}$ imidazole. If the eluted protein partially remained in the reduced form, few crystals of potassium ferricyanide were added to oxidize the flavin. The concentrated protein was passed through the desalting PD10 column in buffer $\mathrm{A}$ to remove traces of the oxidant, $\mathrm{NAD}^{+}$and imidazole. Protein preparations used in the study had $A_{273 / 452}$ ratios $\leq 7.6$.

Spectral measurements - Absorbance spectra were measured on a conventional Cary 300 spectrophotometer in $50 \mathrm{mM}$ phosphate, $\mathrm{pH}$ 7.4. Extinction coefficients for the AIF 
mutants $\left(\varepsilon^{F A D}{ }_{452 n m}\right)$ were determined based on the amount of FAD released after SDS denaturation. ${ }^{29}$ Extinction coefficients for CTC $\left(\varepsilon^{\mathrm{CTC}} 780 \mathrm{~nm}\right)$ were estimated based on the $\varepsilon^{\mathrm{FAD}}{ }_{452 \mathrm{~nm}}$ values. Equilibrium titrations with $\mathrm{NADH}$ were conducted anaerobically in the presence of glucose, glucose oxidase and catalase as described previously. ${ }^{2}$ AIF G262S could slowly accept electrons from glucose oxidase, due to which solutions of this mutant contained a different oxygen scavenging system consisting of protocatechuic acid and protocatechuate dioxygenase $(0.2 \mathrm{mM}$ and 0.1 Units $/ \mathrm{ml}$, respectively; Sigma). ${ }^{30}$ Spectral dissociation constants $\left(K_{s}\right)$ for the AIF-ligand complex were calculated from titration plots by fitting the data to a hyperbolic or quadratic equation (Equations 1 and 2, respectively):

$$
\begin{aligned}
& \Delta \mathrm{A}=\Delta \mathrm{A}_{\mathrm{m}} \cdot[\mathrm{NADH}] /\left(\mathrm{K}_{\mathrm{s}}+[\mathrm{NADH}]\right) \\
& \Delta \mathrm{A}=\Delta \mathrm{A}_{\mathrm{m}} \cdot\left(\left([\mathrm{AIF}]+[\mathrm{NADH}]+\mathrm{K}_{s}\right)-\left(\left(\left([\mathrm{AIF}]+[\mathrm{NADH}]+\mathrm{K}_{s}\right)^{2}\right)-4 \cdot[\mathrm{AIF}] \cdot\right.\right. \\
& \left.[\mathrm{NADH}]))^{0.5}\right) /(2 \cdot[\mathrm{AIF}])
\end{aligned}
$$

where $\Delta A_{m},[A I F]$ and $[N A D H]$ are the maximum absorbance change and the total AIF and NADH concentrations after each titrant addition, respectively. Circular dichroism spectra of the WT and mutant AIF $(5 \mu \mathrm{M})$ were recorded on a Jasco J-720

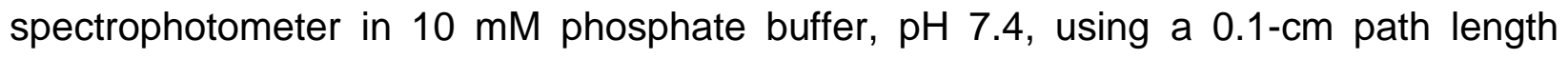
cuvette. Redox potentials of the AIF-bound FAD were determined by the method of Massey ${ }^{31}$ as described in Supplemental Data.

Kinetic measurements - Kinetics of AIF reduction with NADH were measured on a SX.18MV stopped-flow spectrophotometer (Applied Photophysics, UK) in $50 \mathrm{mM}$ phosphate, $\mathrm{pH} 7.4$, after mixing $15 \mu \mathrm{M}$ AIF with 0.6-20 mM NADH. Absorbance changes were monitored at 452 and $770 \mathrm{~nm}$ to follow the FAD reduction and formation of CTC, 
respectively. Kinetic traces were fitted to a double exponential equation using the manufacturer's PROKIN software. The fast phase during the WT, V243L, G308E and G338E AIF reduction accounted for $>90 \%$ of the total absorbance change, and $\sim 70 \%$ for AIF G262S. The limiting rate constant $\left(k_{H T}{ }^{N A D H}\right)$ and kinetic dissociation constant $\left(K_{d}\right)$ were derived from the hyperbolic fits to plots of the observed rate constant for the fast phase $\left(k_{\text {obs }}\right)$ vs. [NADH] using IgorPro (WaveMetrics, Inc.). For AIF G308E, the plot did not reach saturation and, therefore, only the $k_{H T}{ }^{N A D H} / K_{d}$ value was determined by fitting the data to Equation 2:

$$
k_{\mathrm{obs}}=\left(k_{H T}{ }^{\mathrm{NADH}} / \mathrm{K}_{\mathrm{d}}\right) \cdot k_{H T}{ }^{\mathrm{NADH}} \cdot[\mathrm{S}] /\left(k_{\mathrm{HT}}{ }^{\mathrm{NADH}}+\left(k_{H T}{ }^{\mathrm{NADH}} / \mathrm{K}_{\mathrm{d}}\right) \cdot[\mathrm{S}]\right)
$$

The AIF-dependent NADH oxidation reaction and the time course of CTC oxidation by air oxygen were followed on a Cary 300 spectrophotometer at ambient temperatures in $50 \mathrm{mM}$ phosphate, $\mathrm{pH}$ 7.4. Steady-state oxidation of 8-500 $\mu \mathrm{M}$ NADH by $5 \mu \mathrm{M}$ AIF was monitored at $340 \mathrm{~nm}\left(\varepsilon_{340 \mathrm{~nm}}=6.22 \mu \mathrm{M}^{-1} \mathrm{~cm}^{-1}\right)$. The $k_{0 \mathrm{x}}{ }^{\mathrm{NADH}}$ and $\mathrm{K}_{\mathrm{M}}{ }^{\mathrm{NADH}}$ values were derived from hyperbolic fits to the initial velocity vs. [NADH] plots. To estimate the CTC half-lifetime, $18 \mu \mathrm{M}$ AIF proteins were anaerobically reduced with $70 \mu \mathrm{M}$ NADH, after which cuvettes were opened to air and absorbance changes at 452 $\mathrm{nm}$ were recorded over the period of $0.5-17 \mathrm{~h}$, depending on the mutant.

Other measurements - Redox activity measurements, proteolytic digests, crosslinking with $\mathrm{BS}^{3}$, DNA gel retardation assays, and gel filtration chromatography were conducted as described elsewhere..$^{2 ; 3}$

Crystallization and the X-ray structure determination - All AIF mutants were crystallized by a microbatch method under oil. Protein solutions $(0.5 \mu \mathrm{l} ; 15-25 \mathrm{mg} / \mathrm{ml})$ in $0.1 \mathrm{M}$ bisTris propane $\mathrm{pH} 7.0$ were mixed with an equal volume of the precipitant solution $(0.2 \mathrm{M}$ 
ammonium acetate and $20 \%$ poly-ethylene glycol 3350 for AIF G308E; 0.2 M ammonium acetate, $0.1 \mathrm{M}$ Hepes, $\mathrm{pH} 7.5$, and $20 \%$ poly-ethylene glycol 3350 for AIF V243L; $0.2 \mathrm{M}$ lithium sulfate, $0.1 \mathrm{M}$ Tris, $\mathrm{pH} 8.5$, and $25 \%$ poly-ethylene glycol 3350 for AIF G262S and G338E) and covered with paraffin oil. Crystals were harvested 1-2 weeks later and cryoprotected with Paratone-N before freezing in liquid nitrogen. The $\mathrm{X}-$ ray diffraction data were collected at the Stanford Synchrotron Radiation Lightsource beamlines 9-2 and 14-1, and the Advanced Light Source beamlines 8.2.1 and 8.2.2. The $1.40 \AA$ structure of AIF G308E was the first to be determined by molecular replacement with PHASER ${ }^{32}$ and the $1 \mathrm{M} 6 \mathrm{I}$ structure $^{19}$ as a search model. Structures of other mutants were solved to $1.75-1.90 \AA$ resolution using the AIF G308E structure as a search model. Initial models were rebuilt and refined with $\mathrm{COOT}^{33}$ and REFMAC. ${ }^{32}$ Data collection and refinement statistics are summarized in Table 2.

\section{Accession numbers}

The atomic coordinates were deposited to the Protein Data Bank with the ID codes 5FS6, 5FS7, 5FS8 and 5FS9 for AIF V243L, G262S, G308E and G338E, respectively.

\section{Glossary}

CTC - a charge-transfer complex between the 2-electron reduced flavin and oxidized pyridine nucleotide, serving as an electron donor and acceptor, respectively. After receiving two electrons from $\mathrm{NADH}$, AIF dimerizes and forms a $\mathrm{FADH}^{\circ-} \mathrm{NAD}^{+}$charge transfer complex resistant to oxidation. 


\section{Acknowledgements}

This work involves research carried out at the Advanced Light Source and the Stanford Synchrotron Radiation Lightsource, a national user facility operated by Stanford University on behalf of the U.S. Department of Energy, Office of Basic Energy Sciences. The Advanced Light Source is supported by the Director, Office of Science, Office of Basic Energy Sciences, of the U.S. Department of Energy under Contract No. DEAC02-76SF00515. The SSRL Structural Molecular Biology Program is supported by the Department of Energy, Office of Biological and Environmental Research, and by the National Institutes of Health, National Center for Research Resources, Biomedical Technology Program, and the National Institute of General Medical Sciences (including P41GM103393).

\section{References}

1. Susin, S. A., Lorenzo, H. K., Zamzami, N., Marzo, I., Snow, B. E., Brothers, G. M., Mangion, J., Jacotot, E., Costantini, P., Loeffler, M., Larochette, N., Goodlett, D. R., Aebersold, R., Siderovski, D. P., Penninger, J. M. \& Kroemer, G. (1999). Molecular characterization of mitochondrial apoptosis-inducing factor. Nature $397,441-446$.

2. Churbanova, I. Y. \& Sevrioukova, I. F. (2008). Redox-dependent changes in molecular properties of mitochondrial apoptosis-inducing factor. J. Biol. Chem. 283, 5622-5631.

3. Sevrioukova, I. F. (2009). Redox-linked conformational dynamics in apoptosisinducing factor. J. Mol. Biol. 390, 924-938. 
4. Ferreira, P., Villanueva, R., Martinez-Julvez, M., Herguedas, B., Marcuello, C., Fernandez-Silva, P., Cabon, L., Hermoso, J. A., Lostao, A., Susin, S. A. \& Medina, M. (2014). Structural insights into the coenzyme mediated monomerdimer transition of the pro-apoptotic apoptosis inducing factor. Biochemistry 53, $4204-4215$.

5. Mate, M. J., Ortiz-Lombardia, M., Boitel, B., Haouz, A., Tello, D., Susin, S. A., Penninger, J., Kroemer, G. \& Alzari, P. M. (2002). The crystal structure of the mouse apoptosis-inducing factor AIF. Nat. Struct. Biol. 9, 442-6.

6. Elguindy, M. M. \& Nakamaru-Ogiso, E. (2015). Apoptosis-inducing factor (AIF) and its family member protein, AMID, are rotenone-sensitive NADH:ubiquinone oxidoreductases (NDH-2). J. Biol. Chem. 290, 20815-26.

7. Sevrioukova, I. (2011). Apoptosis inducing factor: Structure, function and redox regulation. Antioxid. Redox Sign. 14, 2545-2579.

8. Hangen, E., Feraud, O., Lachkar, S., Mou, H., Doti, N., Fimia, G. M., Lam, N. V., Zhu, C., Godin, I., Muller, K., Chatzi, A., Nuebel, E., Ciccosanti, F., Flamant, S., Benit, P., Perfettini, J. L., Sauvat, A., Bennaceur-Griscelli, A., Ser-Le Roux, K., Gonin, P., Tokatlidis, K., Rustin, P., Piacentini, M., Ruvo, M., Blomgren, K., Kroemer, G. \& Modjtahedi, N. (2015). Interaction between AIF and CHCHD4 regulates respiratory chain biogenesis. Mol. Cell. 58, 1001-1014.

9. Meyer, K., Buettner, S., Ghezzi, D., Zeviani, M., Bano, D. \& Nicotera, P. (2015). Loss of apoptosis-inducing factor critically affects MIA40 function. Cell Death. Dis. 6, e1814. 
10. Chacinska, A., Pfannschmidt, S., Wiedemann, N., Kozjak, V., Sanjuan Szklarz, L. K., Schulze-Specking, A., Truscott, K. N., Guiard, B., Meisinger, C. \& Pfanner, N. (2004). Essential role of Mia40 in import and assembly of mitochondrial intermembrane space proteins. EMBO J. 23, 3735-3746.

11. Hangen, E., Blomgren, K., Benit, P., Kroemer, G. \& Modjtahedi, N. (2010). Life with or without AIF. Trends Biochem. Sci. 35, 278-287.

12. Ghezzi, D., Sevrioukova, I., Invernizzi, F., Lamperti, C., Mora, M., D'Adamo, P., Novara, F., Zuffardi, O., Uziel, G. \& Zeviani, M. (2010). Severe X-linked mitochondrial encephalomyopathy associated with a mutation in apoptosisinducing factor. Am. J. Hum. Genet. 86, 639-649.

13. Rinaldi, C., Grunseich, C., Sevrioukova, I. F., Schindler, A., Horkayne-Szakaly, I., Lamperti, C., Landoure, G., Kennerson, M. L., Burnett, B. G., Bonnemann, C., Biesecker, L. G., Ghezzi, D., Zeviani, M. \& Fischbeck, K. H. (2012). Cowchock syndrome is associated with a mutation in apoptosis-inducing factor. Am. J. Hum. Genet. 91, 1095-1102.

14. Zong, L., Guan, J., Ealy, M., Zhang, Q., Wang, D., Wang, H., Zhao, Y., Shen, Z., Campbell, C. A., Wang, F., Yang, J., Sun, W., Lan, L., Ding, D., Xie, L., Qi, Y., Lou, X., Huang, X., Shi, Q., Chang, S., Xiong, W., Yin, Z., Yu, N., Zhao, H., Wang, J., Salvi, R. J., Petit, C., Smith, R. J. \& Wang, Q. (2015). Mutations in apoptosis-inducing factor cause $\mathrm{X}$-linked recessive auditory neuropathy spectrum disorder. J. Med. Genet. 52, 523-531.

15. Kettwig, M., Schubach, M., Zimmermann, F. A., Klinge, L., Mayr, J. A., Biskup, S., Sperl, W., Gartner, J. \& Huppke, P. (2015). From ventriculomegaly to severe 
muscular atrophy: expansion of the clinical spectrum related to mutations in AlFM1. Mitochondrion 21, 12-18.

16. Ardissone, A., Piscosquito, G., Legati, A., Langella, T., Lamantea, E., Garavaglia, B., Salsano, E., Farina, L., Moroni, I., Pareyson, D. \& Ghezzi, D. (2015). A slowly progressive mitochondrial encephalomyopathy widens the spectrum of AIFM1 disorders. Neurology 84, 2193-2195.

17. Berger, I., Ben-Neriah, Z., Dor-Wolman, T., Shaag, A., Saada, A., Zenvirt, S., Raas-Rothschild, A., Nadjari, M., Kaestner, K. H. \& Elpeleg, O. (2011). Early prenatal ventriculomegaly due to an AIFM1 mutation identified by linkage analysis and whole exome sequencing. Mol. Genet. Metab. 104, 517-520.

18. Diodato, D., Tasca, G., Verrigni, D., D'Amico, A., Rizza, T., Tozzi, G., Martinelli, D., Verardo, M., Invernizzi, F., Nasca, A., Bellacchio, E., Ghezzi, D., Piemonte, F., Dionisi-Vici, C., Carrozzo, R. \& Bertini, E. (2016). A novel AlFM1 mutation expands the phenotype to an infantile motor neuron disease. Eur. J. Hum. Genet. 24, 463-466.

19. Ye, H., Cande, C., Stephanou, N. C., Jiang, S., Gurbuxani, S., Larochette, N., Daugas, E., Garrido, C., Kroemer, G. \& Wu, H. (2002). DNA binding is required for the apoptogenic action of apoptosis inducing factor. Nat. Struct. Biol. 9, 680684.

20. Sorrentino, L., Calogero, A. M., Pandini, V., Vanoni, M. A., Sevrioukova, I. F. \& Aliverti, A. (2015). Key role of the adenylate moiety and integrity of the adenylatebinding site for the NAD/H binding to mitochondrial apoptosis inducing factor. Biochemistry 54, 6996-7009. 
21. Susin, S. A., Zamzami, N., Castedo, M., Hirsch, T., Marchetti, P., Macho, A., Daugas, E., Geuskens, M. \& Kroemer, G. (1996). Bcl-2 inhibits the mitochondrial release of an apoptogenic protease. J. Exp. Med. 184, 1331-1341.

22. Zamzami, N., Susin, S. A., Marchetti, P., Hirsch, T., Gomez-Monterrey, I., Castedo, M. \& Kroemer, G. (1996). Mitochondrial control of nuclear apoptosis. J. Exp. Med. 183, 1533-1544.

23. Klein, J. A., Longo-Guess, C. M., Rossmann, M. P., Seburn, K. L., Hurd, R. E., Frankel, W. N., Bronson, R. T. \& Ackerman, S. L. (2002). The harlequin mouse mutation downregulates apoptosis-inducing factor. Nature 419, 367-374.

24. Cheung, E. C., Joza, N., Steenaart, N. A., McClellan, K. A., Neuspiel, M., McNamara, S., MacLaurin, J. G., Rippstein, P., Park, D. S., Shore, G. C., McBride, H. M., Penninger, J. M. \& Slack, R. S. (2006). Dissociating the dual roles of apoptosis-inducing factor in maintaining mitochondrial structure and apoptosis. EMBO J. 25, 4061-4073.

25. Stambolsky, P., Weisz, L., Shats, I., Klein, Y., Goldfinger, N., Oren, M. \& Rotter, V. (2006). Regulation of AIF expression by p53. Cell Death Differ. 13, 2140-9.

26. Burton, T. R., Eisenstat, D. D. \& Gibson, S. B. (2009). BNIP3 (Bcl-2 19 kDa interacting protein) acts as transcriptional repressor of apoptosis-inducing factor expression preventing cell death in human malignant gliomas. J. Neurosci. 29, 4189-99.

27. Chen, J. T., Huang, C. Y., Chiang, Y. Y., Chen, W. H., Chiou, S. H., Chen, C. Y. \& Chow, K. C. (2008). HGF increases cisplatin resistance via down-regulation of AIF in lung cancer cells. Am. J. Respir. Cell. Mol. Biol. 38, 559-65. 
28. Shen, S. M., Yu, Y., Wu, Z. X., Zheng, Y., Chen, G. Q. \& Wang, L. S. (2011). Apoptosis-inducing factor is a target gene of C/EBPalpha and participates in adipocyte differentiation. FEBS Lett. 585, 2307-12.

29. Prongay, A. J., Engelke, D. R. \& Williams, C. H., Jr. (1989). Characterization of two active site mutations of thioredoxin reductase from Escherichia coli. J. Biol. Chem. 264, 2656-2664.

30. Patil, P. V. \& Ballou, D. P. (2000). The use of protocatechuate dioxygenase for maintaining anaerobic conditions in biochemical experiments. Anal. Biochem. 286, 187-192.

31. Massey, V. (1991). A simple method for the determination of redox potentials. In: Flavins and Flavoproteins (Curti, B., Rochi, S., and Zanetti, G., Eds.), pp. 59-66, Walter DeGruyter \& Co., Berlin.

32. CCP4. (1994). Collaborative computational project number 4. The CCP4 suite programs for protein crystallography. Acta Crystallogr. Section D 50, 760-763.

33. Emsley, P., Lohkamp, B., Scott, W. G. \& Cowtan, K. (2010). Features and development of Coot. Acta Crystallogr. Section D 66, 486-501.

\section{Figure legends}

Figure 1. A, Absorbance spectra of the oxidized (solid lines) and NADH-reduced (dotted lines) WT AIF and mutants. A various excess of NADH (indicated) was used to fully reduce FAD. B, Far UV circular dichroism spectra of the WT and mutant AIF. 
Figure 2. Anaerobic equilibrium titrations of the WT and mutant AIF with NADH. All experiments were carried out in the presence of an oxygen scavenging system as described in Materials and Methods. Insets depict dependences of the percentage of reduced $F A D$ on the NADH:FAD ratio. Spectral dissociation constants $\left(K_{s}{ }^{N A D H}\right)$ derived from the quadratic (A-C) and hyperbolic fits (D, E) are listed in Table 1.

Figure 3. Transient kinetics of AIF reduction with $\mathrm{NADH}$.

A and B, Kinetics of the FAD reduction and CTC formation recorded at 452 and 770 $\mathrm{nm}$, respectively, upon mixing $15 \mu \mathrm{M}$ AIF with $10 \mathrm{mM} \mathrm{NADH}$ in $50 \mathrm{mM}$ phosphate buffer, pH 7.4. The best fits were achieved using a double exponential decay. For WT, V243L, G308E and G338E AIF, the fast kinetic phase accounted for $>90 \%$ of the total absorbance change, and the rate constants derived for the 452 and $770 \mathrm{~nm}$ kinetics were virtually identical. For AIF G262S, the percentage of the fast phase for the FAD reduction reaction was decreased to $70 \%$, whereas absorbance changes at $770 \mathrm{~nm}$ were more complex due to slow isomerization of CTC into species with a weaker absorption in the long-wavelength region. The displayed $770 \mathrm{~nm}$ trace was fit to a triple exponential equation, with the derived rate constants of $0.26,0.13$ and $0.025 \mathrm{~s}^{-1}$. Fitting curves are depicted as solid black or white lines. The residual plots show the fitting accuracy.

C and $\mathbf{D}$, Dependence of the observed rate constants for the fast phase ( $\left.k_{\mathrm{obs}}\right)$ on NADH concentration. The limiting rate constant $\left(\mathrm{K} H \mathrm{~T}^{\mathrm{NADH}}\right)$ and $\mathrm{K}_{d} \mathrm{NADH}$ values derived from the hyperbolic fits are given in Table 1 . Since the $k_{\text {obs }}$ vs. [NADH] plot for the G308E mutant 
did not reach saturation, only the $k_{H T}{ }^{N A D H} / K_{d} N A D H$ parameter was determined as described in Materials and Methods.

Figure 4. A, Dependence of the observed rate constants for the AIF-catalyzed NADH oxidation reaction on NADH concentration. The y-scale for the G262S mutant is shown on the right. B, Kinetics of CTC oxidation by air oxygen. Proteins were anaerobically pre-reduced with a 4-fold excess of $\mathrm{NADH}$, after which cuvettes were opened to air and absorbance changes at $452 \mathrm{~nm}$ were recorded at room temperature. A dotted line shows the $A_{452 \mathrm{~nm}}$ value for the fully oxidized WT and G308E AIF, measured before the experiment and used for the CTC half-lifetime $\left(t^{\mathrm{CTC}}{ }_{1 / 2}\right)$ calculation. The $t^{\mathrm{CTC}}$ 1/2 values, as well as the limiting rate constant $\left(k_{\mathrm{ox}}{ }^{\mathrm{NADH}}\right)$ and $\mathrm{K}_{\mathrm{M}}{ }^{\mathrm{NADH}}$ derived from the hyperbolic fits to plots in panel $\mathbf{A}$ are listed in Table 1.

Figure 5. A, Gel filtration elution profiles showing dimerization of AIF V243L, G308E and G338E upon reduction with NADH. Experiments were conducted aerobically using an FPLC Superdex 200 column. B, Chemical crosslinking of the NADH-reduced dimers of AIF G262S with $\mathrm{BS}^{3}$. An intact protein and conjugated dimers were separated under denaturing conditions on a $12 \%$ polyacrylamide gel. C, Limited trypsinolysis of the oxidized and NADH-reduced WT and mutant AIF. The digest patterns are virtually identical, suggesting similarity in folding and organization of the regulatory peptide. D, Mutational effect on the AIF-DNA interaction. Equal amounts of the WT and mutant AIF $(100 \mu \mathrm{g})$ were preincubated for 15 min with $250 \mathrm{ng}$ of a $100 \mathrm{bp}$ DNA ladder (New 
England Biolabs) and, after separation on a $2 \%$ agarose gel, visualized with ethidium bromide.

Figure 6. A, Structural superposition of WT AIF (PDB ID 4BV6; black) and the V243L (pink), G262S (green), G308E (beige) and G338E (cyan) mutants. The FAD and mutated residues are displayed in cpk and sphere representation, respectively. Neither mutation alters the AIF fold.

B, Superposition of the WT and V243L AIF (in gray/black and pink, respectively). The $1.90 \AA$ crystal structure of the V243L mutant indicates that only minor side chain rearrangement in the neighboring residues is needed to accommodate Leu at position 243. The $2 F_{o}-F_{c}$ electron density map is contoured at $1.5 \sigma$.

C, Superposition of the WT and G308E AIF (in gray and beige, respectively). The 1.40 $\AA$ crystal structure of AIF G308E shows that introduction of Glu at position 308 does not affect the backbone conformation but triggers rearrangement of the Glu336 and Lys342 side chains. The $2 \mathrm{~F}_{\mathrm{o}}-\mathrm{F}_{\mathrm{c}}$ electron density map is contoured at $1.5 \sigma$. Water molecules and hydrogen bonds are depicted as red spheres and yellow dotted lines, respectively. D, Superposition of the WT and G338E AIF (in gray and cyan, respectively). Only minor conformational changes are observed in the $1.75 \AA$ crystal structure of the G338E mutant. The Glu338 side chain is well ordered and H-bonded to Lys337, Ser349 and Asn350 directly or via water molecules (shown as red spheres). The $2 F_{0}-F_{c}$ electron density map is contoured at $1 \sigma$. 
Figure 7. A, Superposition of the NADH-reduced WT AIF $\left(\mathrm{AlF}_{\text {red }}{ }^{-N A D^{+}}\right.$; PDB ID 4BUR; molecule B) and the G308E mutant (in magenta and beige, respectively). $\mathrm{NAD}^{+}$is in green and stick representation. Only side chains of the key residues are displayed, and $\mathrm{H}$-bonds are shown as dotted lines. The hydrogen bond between the Lys342:NZ and $\mathrm{NAD}^{+}: \mathrm{O} 1 \mathrm{~A}$ atoms is not observed in three other molecules of the $3.0 \AA$ 4 $\mathrm{BUR}$ structure, but is formed in both molecules of the analogous $2.24 \AA$ structure of murine AIF (PDB ID 3GD4; $92 \%$ identical to the human isoform). In is possible, therefore, that Glu at position 308 not only leads to steric hindrance with the adenylate ribose but also rearranges and disengages the Glu336 and Lys342 side chains from the interactions stabilizing the $\mathrm{AlF}_{\text {red- }} \mathrm{NAD}^{+}$complex.

B, Structural superposition of the G338E mutant (cyan/green) and WT AIF red-NAD (4BUR; gray/lavender). In $\mathrm{AlF}_{\text {red }}-\mathrm{NAD}^{+}$, the surface adjacent to the 553-556 portion of the regulatory peptide (shown in lavender) interacts with the symmetry related molecule (pink; dotted lines represent salt bridges), which could cause displacement of the nearby $\alpha$-helix and shift Glu346 toward residue 338. Since it is unknown how this surface would look without crystal packing constraints, the G338E mutational effect on the regulatory peptide folding cannot be accurately defined. The AIF G338E structure suggests, however, that only minor adjustments (e.g., a different Glu346 rotamer) could be needed to accommodate the regulatory peptide in orientation observed in the WT $\mathrm{AlF}_{\text {red }}-\mathrm{NAD}^{+}$structure.

Figure 8. Structural changes induced by the G262S mutation. 
A, Superposition of the WT (4BV6) and G262S AIF structures (shown in gray and green, respectively), with the mutation site indicated by an arrow. A notable $(\sim 1.0 \AA)$ shift in the isoalloxazine portion of FAD is due to a slightly distinct domain-domain orientation in WT AIF caused by different crystal packing.

B, Superposition of the active sites/FAD-binding domains of WT (gray), G262S (green) and V243L AIF (beige). The V243L mutant was used for comparison because it crystallizes in the same space group and, overall, is structurally more similar to AIF G262S than WT.

C, The FAD conformation in WT, V243L and G262S AIF (shown in black, cyan and orange, respectively). Only part of the flavin is displayed to better show a $\sim 0.2 \AA$ distortion in the isoalloxazine/ribitol portion caused by the G262S mutation.

D, An up-close view at the mutation site (si-face of the flavin ring). The AIF G262S and V243L structures are in green/orange and gray, respectively. Introduction of a polar Ser residue at position 262 triggers reorganization of the neighboring Arg285, Asp438, Arg451 and Glu453, leading to formation of an extensive H-bonding network that includes preexisting and newly recruited water molecules (shown as red crosses and spheres, respectively).

E, A different view at the mutation site, with the $\mathrm{NAD}^{+}$molecule (in cyan) modeled based on the 4BUR structure. The bulkier Ser262 forces Leu400 to shift and adopt a rotamer that is only $2.9 \AA$ away from the $N A D^{+}$ribose (indicated by arrows). The $2 F_{0}-F_{c}$ electron density map is contoured at $1.3 \sigma$.

F, The active site cavity in AIF G262S (green/yellow/magenta) and V243L (gray/blue). The displaced Leu400 narrows the $\mathrm{NAD}^{+}(\mathrm{H})$-binding channel by $1.3 \AA$ in the region 
where the ribose/nicotinamide portion bends to align with the FAD isoalloxazine. $A$ decrease in the maneuvering space and lower conformational flexibility due to formation of the Ser262-mediated $\mathrm{H}$-bond cluster could prevent $\mathrm{NAD}^{+}(\mathrm{H})$ from adapting an optimal orientation which, in turn, could weaken/disfavor $\pi-\pi$ stacking interactions between the nicotinamide and isoalloxazine rings, and destabilize the charge transfer complex. 
Table 1. Spectral and redox properties of the wild type and mutants of human AIF

\begin{tabular}{|c|c|c|c|c|c|}
\hline & WT & V243L & G262S & G308E & G338E \\
\hline$\varepsilon^{\text {FAD }}{ }_{452 \mathrm{~nm}}\left(\mathrm{mM}^{-1} \mathrm{~cm}^{-1}\right)$ & $13.2+0.2$ & $13.3 \pm 0.2$ & $13.5 \pm 0.2$ & $13.4 \pm 0.1$ & $13.1 \pm 0.2$ \\
\hline$\varepsilon^{C T C} 780 \mathrm{~nm}\left(\mathrm{mM}^{-1} \mathrm{~cm}^{-1}\right)$ & $2.9+0.2$ & $2.9 \pm 0.1$ & $1.6 \pm 0.2$ & $2.9 \pm 0.1$ & $2.7 \pm 0.2$ \\
\hline$E_{\mathrm{m}, 8}(\mathrm{mV})$ & $-353 \pm 5$ & $-362 \pm 6$ & $-389 \pm 5$ & $-356 \pm 5$ & $-364 \pm 8$ \\
\hline $\mathrm{K}_{\mathrm{s}}^{\mathrm{NADH}}(\mu \mathrm{M})$ & $0.11 \pm 0.01$ & $0.13 \pm 0.02$ & $32.2 \pm 0.9$ & $8.0 \pm 0.7$ & $0.17 \pm 0.03$ \\
\hline$k_{\mathrm{HT}}{ }^{\mathrm{NADH}}\left(\mathrm{s}^{-1}\right)$ & $0.88 \pm 0.04$ & $0.98 \pm 0.05$ & $0.37 \pm 0.02^{\mathrm{a}}$ & - & $0.45 \pm 0.02$ \\
\hline $\mathrm{K}_{\mathrm{d}}^{\mathrm{NADH}}(\mathrm{mM})$ & $1.51 \pm 0.21$ & $1.53 \pm 0.24$ & $0.92 \pm 0.16$ & - & $2.11 \pm 0.24$ \\
\hline$k_{H T}{ }^{N A D H} / K_{d}{ }^{N A D H}\left(s^{-1} \mathrm{mM}^{-1}\right)$ & 0.58 & 0.64 & 0.40 & $0.0046^{b}$ & 0.21 \\
\hline$k_{\text {Ox }}{ }^{\mathrm{NADH}} \times 10^{3}\left(\mathrm{~min}^{-1}\right)$ & $1.6 \pm 0.1$ & $2.6 \pm 0.1$ & $188 \pm 3$ & $0.77 \pm 0.03$ & $5.8 \pm 0.1$ \\
\hline $\mathrm{K}_{\mathrm{M}}^{\mathrm{NADH}}(\mu \mathrm{M})$ & $45 \pm 6$ & $45 \pm 6$ & $258 \pm 11$ & $49 \pm 5$ & $29 \pm 2$ \\
\hline$k_{\mathrm{ox}}{ }^{\mathrm{NADH}} / \mathrm{K}_{\mathrm{M}}{ }^{\mathrm{NADH}} \times 10^{2}\left(\mathrm{~min}^{-1} \mu \mathrm{M}^{-1}\right)$ & 3.6 & 5.8 & 73 & 1.6 & 20 \\
\hline \multirow[t]{2}{*}{$t_{1 / 2}^{\mathrm{CTC}}(\mathrm{h})$} & $11 \pm 0.5$ & $5.6 \pm 0.3$ & $0.10 \pm 0.01$ & $5.0 \pm 0.2$ & $3.3 \pm 0.2$ \\
\hline & \multicolumn{3}{|c|}{ DCIP reduction ${ }^{c}$} & & \\
\hline$k_{\text {cat }}\left(\min ^{-1}\right)$ & $86 \pm 7$ & $54 \pm 4$ & $100 \pm 16$ & $-{ }^{d}$ & $19 \pm 2$ \\
\hline $\mathrm{K}_{\mathrm{M}}^{\mathrm{DCIP}}(\mu \mathrm{M})$ & $138 \pm 18$ & $135 \pm 24$ & $516 \pm 96$ & & $121 \pm 33$ \\
\hline $\mathrm{K}_{\mathrm{M}}^{\mathrm{NADH}}(\mathrm{mM})$ & $0.51 \pm 0.11$ & $0.38 \pm 0.17$ & $0.14 \pm 0.03$ & & $0.46 \pm 0.10$ \\
\hline \multirow[t]{2}{*}{$k_{\text {cat }} / \mathrm{K}_{\mathrm{M}}^{\mathrm{NADH}}\left(\mathrm{mM}^{-1} \mathrm{~min}^{-1}\right)$} & 169 & 142 & 714 & & 41 \\
\hline & \multicolumn{3}{|c|}{$\begin{array}{l}142 \\
\text { cytochrome c reduction }^{e}\end{array}$} & & \\
\hline$k_{\text {cat }}\left(\min ^{-1}\right)$ & $24 \pm 5$ & $21 \pm 5$ & $9 \pm 1$ & $-{ }^{d}$ & $11 \pm 2$ \\
\hline $\mathrm{K}_{\mathrm{M}}{ }^{\mathrm{cyt} c}(\mu \mathrm{M})$ & $26 \pm 13$ & $42 \pm 12$ & $17 \pm 1$ & & $59 \pm 10$ \\
\hline $\mathrm{K}_{\mathrm{M}}^{\mathrm{NADH}}(\mathrm{mM})$ & $0.27 \pm 0.02$ & $0.08 \pm 0.02$ & $0.031 \pm 0.005$ & & $0.33 \pm 0.06$ \\
\hline$k_{\text {cat }} / K_{M}{ }^{\mathrm{NADH}}\left(\mathrm{mM}^{-1} \mathrm{~min}^{-1}\right)$ & 89 & 263 & 290 & & 33 \\
\hline
\end{tabular}

a - The limiting rate constant for the slow phase, during which $\sim 30 \%$ of the total absorbance change takes place, is $0.14 \pm 0.02 \mathrm{~s}^{-1}$.

b - Only the $k_{H T}{ }^{N A D H} / K_{d}$ NADH value was determined because the $k_{\text {obs }}$ Vs. [NADH] plot for AIF G308E does not reach saturation under experimental conditions.

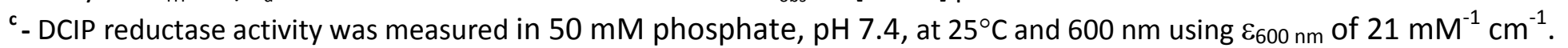

d-Undetectable under experimental conditions.

e - Cytochrome $c$ reductase activity was measured in $5 \mathrm{mM}$ phosphate, $\mathrm{pH} 7.4$, at $25^{\circ} \mathrm{C}$ and $550 \mathrm{~nm}$ using $\varepsilon_{550 \mathrm{~nm}}$ of $21 \mathrm{mM}^{-1} \mathrm{~cm}^{-1}$. 
Table 2. Data collection and refinement statistics

\begin{tabular}{|c|c|c|c|c|}
\hline $\begin{array}{l}\text { Variant } \\
\text { PDB ID }\end{array}$ & $\begin{array}{l}\text { V243L } \\
5 F S 6\end{array}$ & $\begin{array}{l}\text { G262S } \\
\text { 5FS7 }\end{array}$ & $\begin{array}{l}\text { G308E } \\
\text { 5FS8 }\end{array}$ & $\begin{array}{l}\text { G338E } \\
\text { 5FS9 }\end{array}$ \\
\hline \multicolumn{5}{|l|}{ Data statistics } \\
\hline $\begin{array}{l}\text { Space group } \\
\text { Unit cell parameters }\end{array}$ & $\begin{array}{l}\mathrm{P} 2_{1} 2_{1} 2_{1} \\
a=91 \AA, b=114 \AA \\
c=121 \AA ; \alpha, \beta, \gamma=90^{\circ}\end{array}$ & $\begin{array}{l}\mathrm{P} 2{ }_{1}{ }_{1} 2_{1} \\
a=91 \AA, b=115 \AA \\
c=121 \AA ; \alpha, \beta, \gamma=90^{\circ}\end{array}$ & $\begin{array}{l}\mathrm{P} 2_{1} \\
a=51 \AA, b=90 \AA \\
c=60 \AA ; \alpha, \gamma=90^{\circ} \\
\beta=94^{\circ}\end{array}$ & $\begin{array}{l}\mathrm{P} 2_{1} 2_{1} 2_{1} \\
a=91 \AA, b=115 \AA \\
c=122 \AA ; \alpha, \beta, \gamma=90^{\circ}\end{array}$ \\
\hline \multicolumn{5}{|l|}{ Molecules per } \\
\hline asymmetric unit & 2 & 2 & 1 & 2 \\
\hline Resolution range $(\AA)$ & $83.20-1.90(2.00-1.90)^{\mathbf{a}}$ & $83.12-1.85(1.95-1.85)$ & $50.79-1.40(1.48-1.40)$ & $61.44-1.75(1.84-1.75)$ \\
\hline Total reflections & 412,637 & 585,891 & 370,231 & 684,799 \\
\hline Unique reflections & 99,250 & 106,911 & 102,452 & 128,212 \\
\hline Redundancy & $4.2(4.0)$ & $5.5(5.3)$ & $3.6(2.9)$ & $5.3(5.2)$ \\
\hline Completeness & $99.3(97.8)$ & $98.6(97.4)$ & $97.1(88.7)$ & $99.8(99.5)$ \\
\hline Average $/ / \sigma l$ & $7.4(1.6)$ & $9.2(1.5)$ & $9.4(1.5)$ & $8.3(0.9)$ \\
\hline$R_{\text {merge }}$ & $0.122(0.789)$ & $0.116(1.041)$ & $0.061(0.622)$ & $0.096(1.482)$ \\
\hline $\mathrm{R}_{\text {pim }}$ & $0.067(0.442)$ & $0.054(0.497)$ & $0.035(0.436)$ & $0.045(0.793)$ \\
\hline CC $1 / 2$ & $0.994(0.589)$ & $0.996(0.606)$ & $0.997(0.722)$ & $0.995(0.485)$ \\
\hline \multicolumn{5}{|l|}{ Refinement statistics } \\
\hline $\begin{array}{l}R / R_{\text {free }} \text { b } \\
\text { Number of atoms: }\end{array}$ & $17.2 / 20.7$ & $17.9 / 21.7$ & $16.4 / 19.3$ & $17.6 / 20.0$ \\
\hline Protein & 7156 & 7034 & 3873 & 7236 \\
\hline Solvent & 908 & 1079 & 657 & 541 \\
\hline \multicolumn{5}{|l|}{ R.m.s. deviations: } \\
\hline Bond lengths, $\AA$ & 0.012 & 0.010 & 0.011 & 0.011 \\
\hline Bond angles, ${ }^{\circ}$ & 1.609 & 1.444 & 1.540 & 1.440 \\
\hline
\end{tabular}

a Values in brackets are for the highest resolution shell.

${ }^{b} R_{\text {free }}$ was calculated from a subset of $5 \%$ of the data that were excluded during refinement. 
Table 3. Comparison of the AIFM1 mutational effects on the phenotypic features and properties of isolated AIF

\begin{tabular}{|c|c|c|c|c|c|c|}
\hline \multicolumn{7}{|c|}{ AIFM1 Mutation } \\
\hline & $\mathrm{G} 308 \mathrm{E}^{\mathrm{a}}$ & $\Delta \mathrm{R} 201^{\mathrm{b}}$ & G338E ${ }^{c}$ & $\mathrm{G}_{262 S^{d}}$ & $V 243 L^{e}$ & $E 493 V^{f}$ \\
\hline Onset time & prenatal & within $1^{\text {st }}$ year & 2-5 months & 1 year & 2.5 years & childhood \\
\hline $\begin{array}{l}\text { Clinical } \\
\text { symptoms }\end{array}$ & $\begin{array}{l}\text { encephalo- } \\
\text { myopathy }\end{array}$ & $\begin{array}{l}\text { encephalo- } \\
\text { myopathy }\end{array}$ & $\begin{array}{l}\text { ataxia, } \\
\text { axonal } \\
\text { neuropathy }\end{array}$ & $\begin{array}{l}\text { encephalopathy, } \\
\text { motor axonal } \\
\text { neuropathy }\end{array}$ & $\begin{array}{c}\text { muscle atrophy, } \\
\text { ataxia, } \\
\text { hearing loss }\end{array}$ & $\begin{array}{l}\text { axonal neuropathy, } \\
\text { deafness, } \\
\text { mental retardation }\end{array}$ \\
\hline Progression & rapid & rapid & rapid, & rapid & slow & slow \\
\hline Lifespan & early death & $\begin{array}{l}\text { early death or } \\
\text { incapacitation }\end{array}$ & $\begin{array}{c}\text { early } \\
\text { incapacitation }\end{array}$ & $\begin{array}{l}\text { alive at } 39 \text {, } \\
\text { wheelchair-bound }\end{array}$ & $\begin{array}{c}\text { alive at } 11, \\
\text { wheelchair-bound }\end{array}$ & normal \\
\hline OXPHOS defects & $\begin{array}{l}\text { c.I }(\downarrow 80 \%) \\
\text { c.III }(\downarrow 40 \%) \\
\text { c.IV }(\downarrow 90 \%)\end{array}$ & $\begin{array}{c}\text { c.III }(\downarrow 35 \%) \\
\text { c.IV }(\downarrow 45-90 \%)\end{array}$ & c.IV $(\downarrow 20-45 \%)$ & $\begin{array}{l}\text { c.I }(\downarrow 80 \%) \\
\text { c.III }(\downarrow 40 \%)\end{array}$ & c.I $(\downarrow 40 \%)$ & none \\
\hline $\begin{array}{l}\text { Caspase- independent } \\
\text { apoptosis }\end{array}$ & ND & $\uparrow$ & ND & ND & ND & $\uparrow$ \\
\hline $\begin{array}{l}\text { AIF expression } \\
\text { level }\end{array}$ & ND & normal & $\downarrow \sim 80 \%$ & $\downarrow 60 \%$ & $\downarrow>90 \%$ & normal \\
\hline $\begin{array}{l}\text { Changes in the AIF pro } \\
\text { Crystal structure }\end{array}$ & $\begin{array}{c}\text { operties } \\
-\end{array}$ & + & - & + & - & - \\
\hline Redox activity & $\downarrow \downarrow \downarrow$ & $\uparrow \uparrow$ & $\downarrow$ & $\uparrow \uparrow$ & - & $\uparrow$ \\
\hline DNA binding & - & + & - & - & - & + \\
\hline
\end{tabular}

C.I - IV - respiratory complexes I - IV; ND - not determined; $\downarrow$ - decreased; $\downarrow \downarrow \downarrow$ - drastically decreased; $\uparrow$ and $\uparrow \uparrow$ - moderately and significantly increased. ${ }^{\mathbf{a}} 16$ and this study; ${ }^{\mathbf{b}}{ }^{11} ;{ }^{\mathrm{c}}{ }^{17}$ and this study; ${ }^{\mathrm{d} 15}$ and this study; ${ }^{14}$ and this study; ${ }^{1} 12$ 
Figure 1
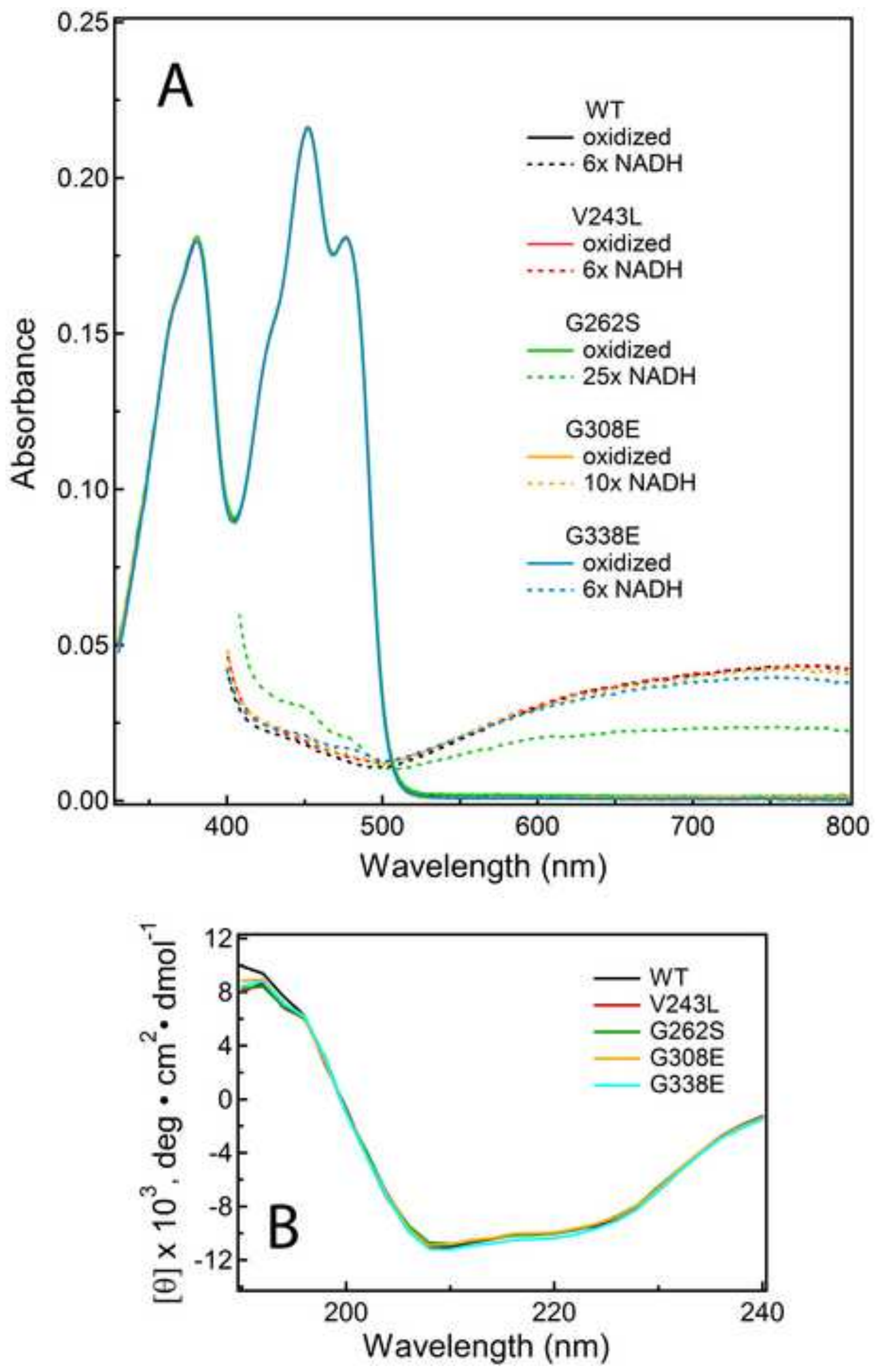

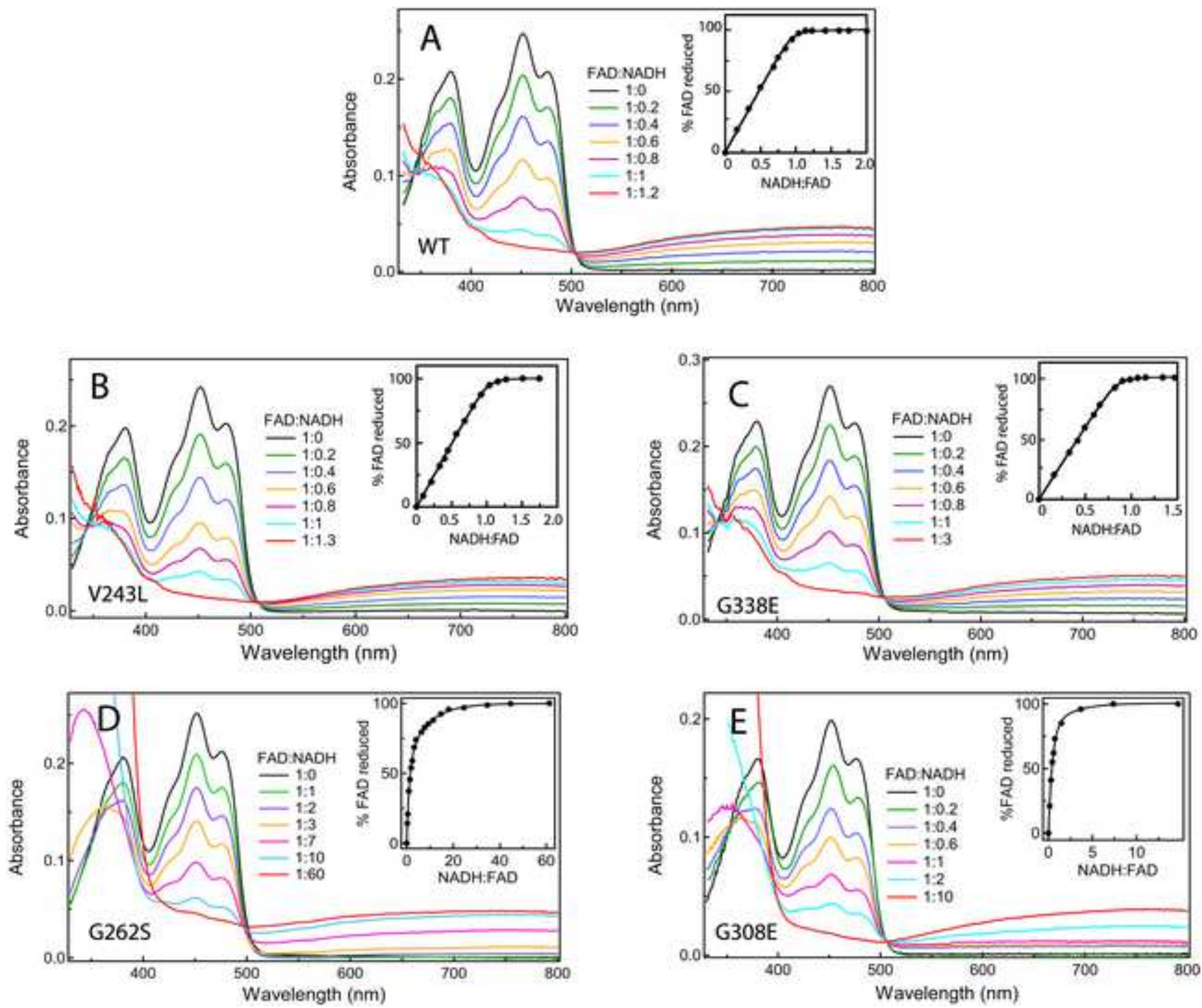

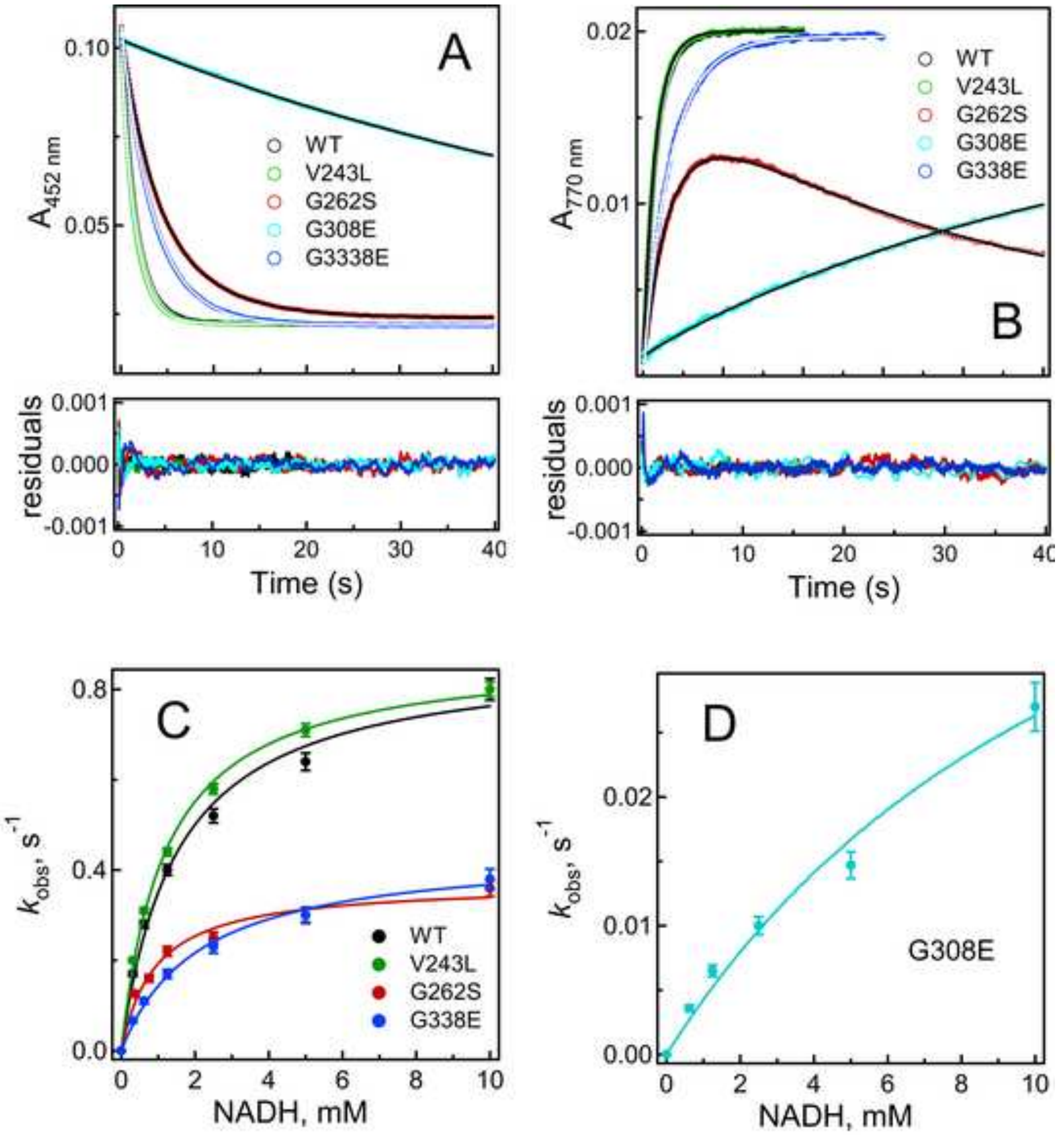

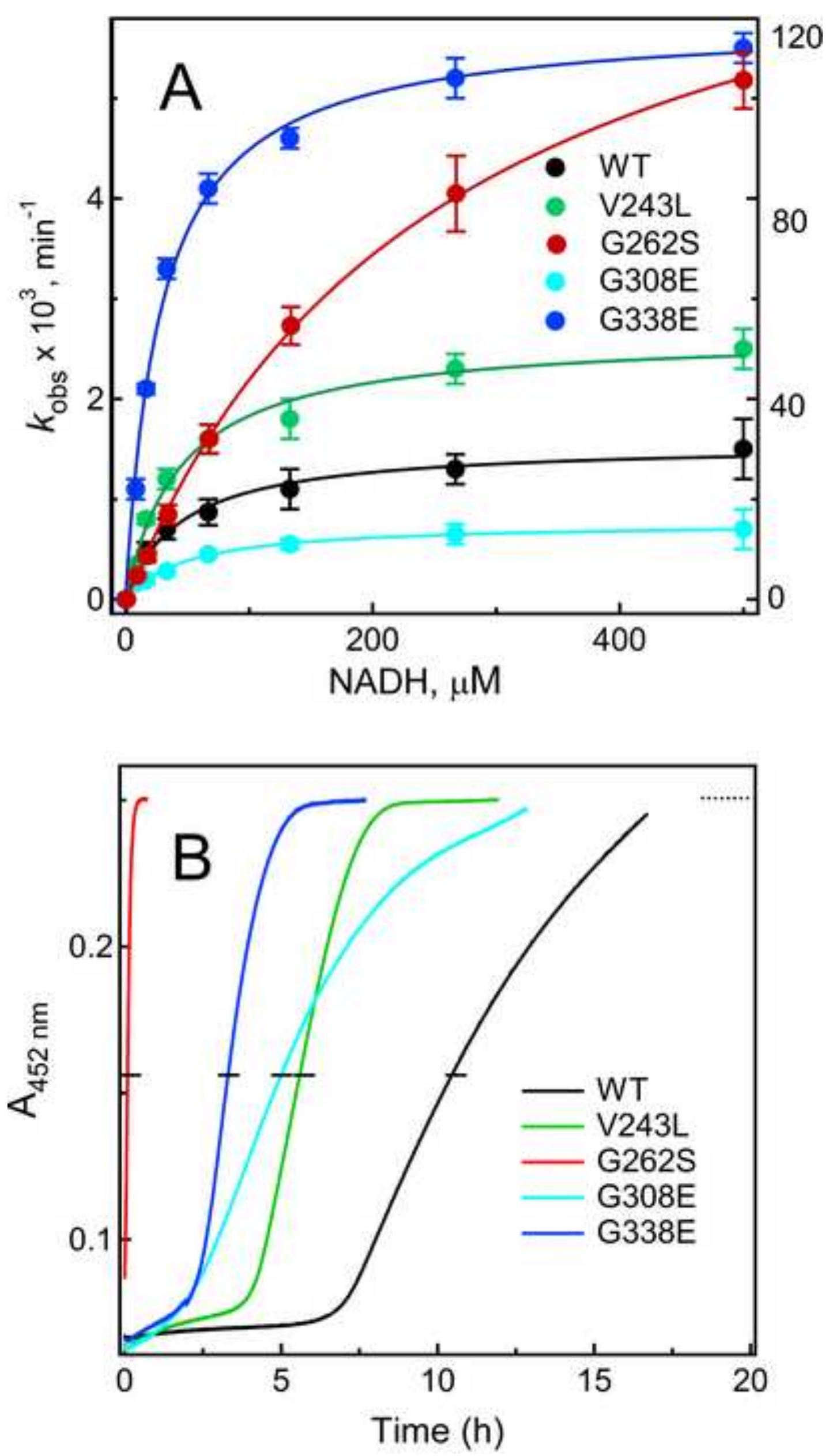

Figure 4 


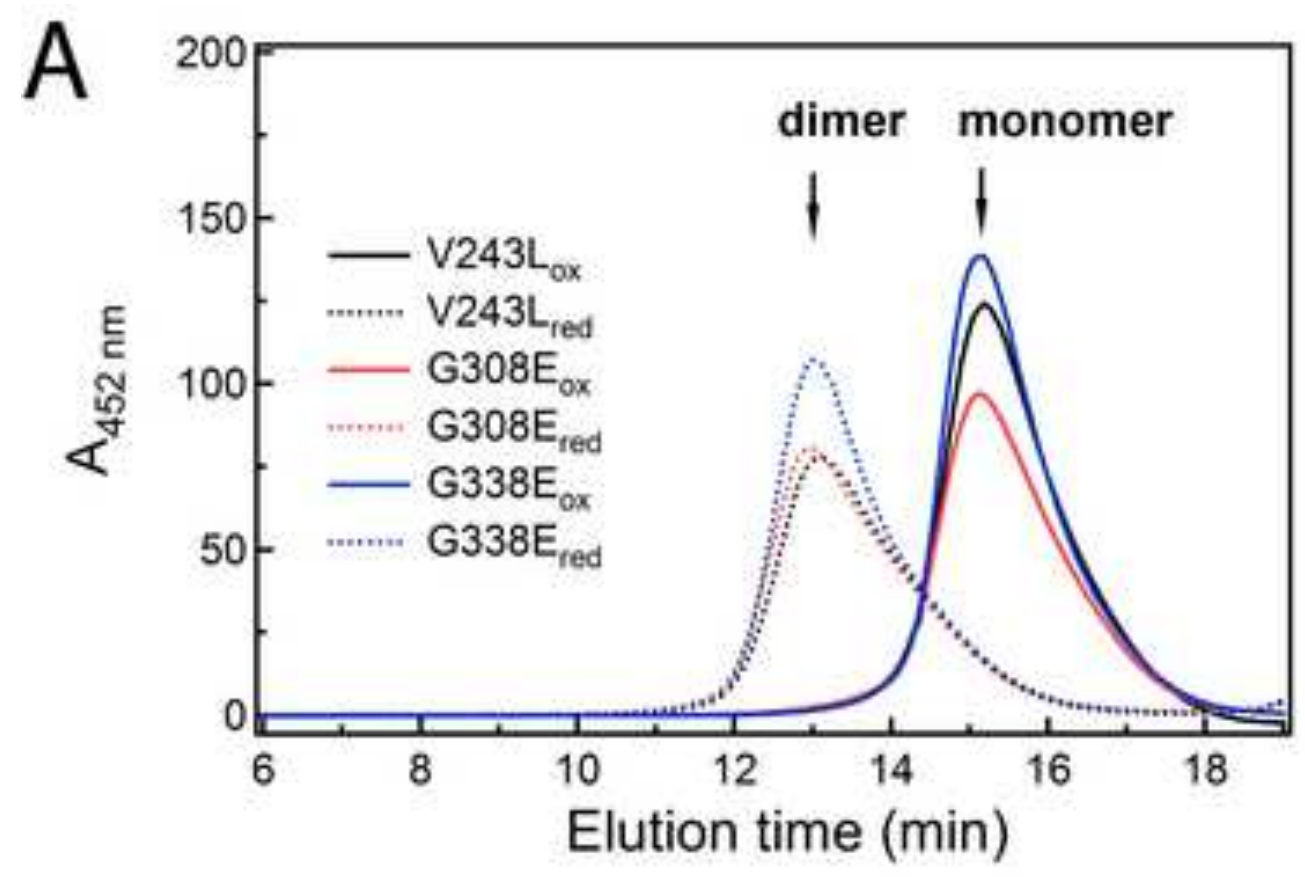

B $\begin{array}{lrr}\mathrm{BS}^{3} & - & + \\ \text { time }(\min ) & 15 & 30\end{array}$

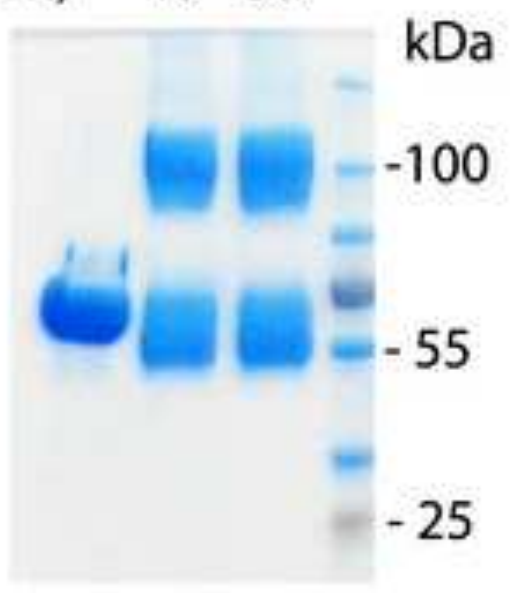

C
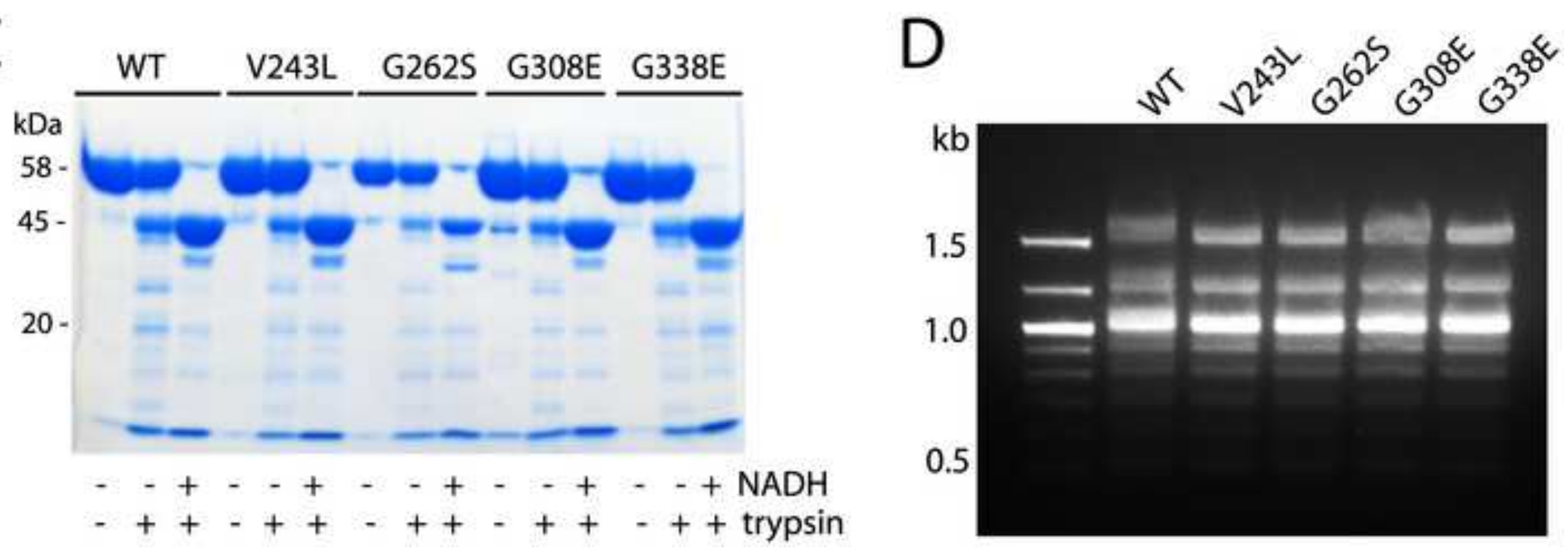

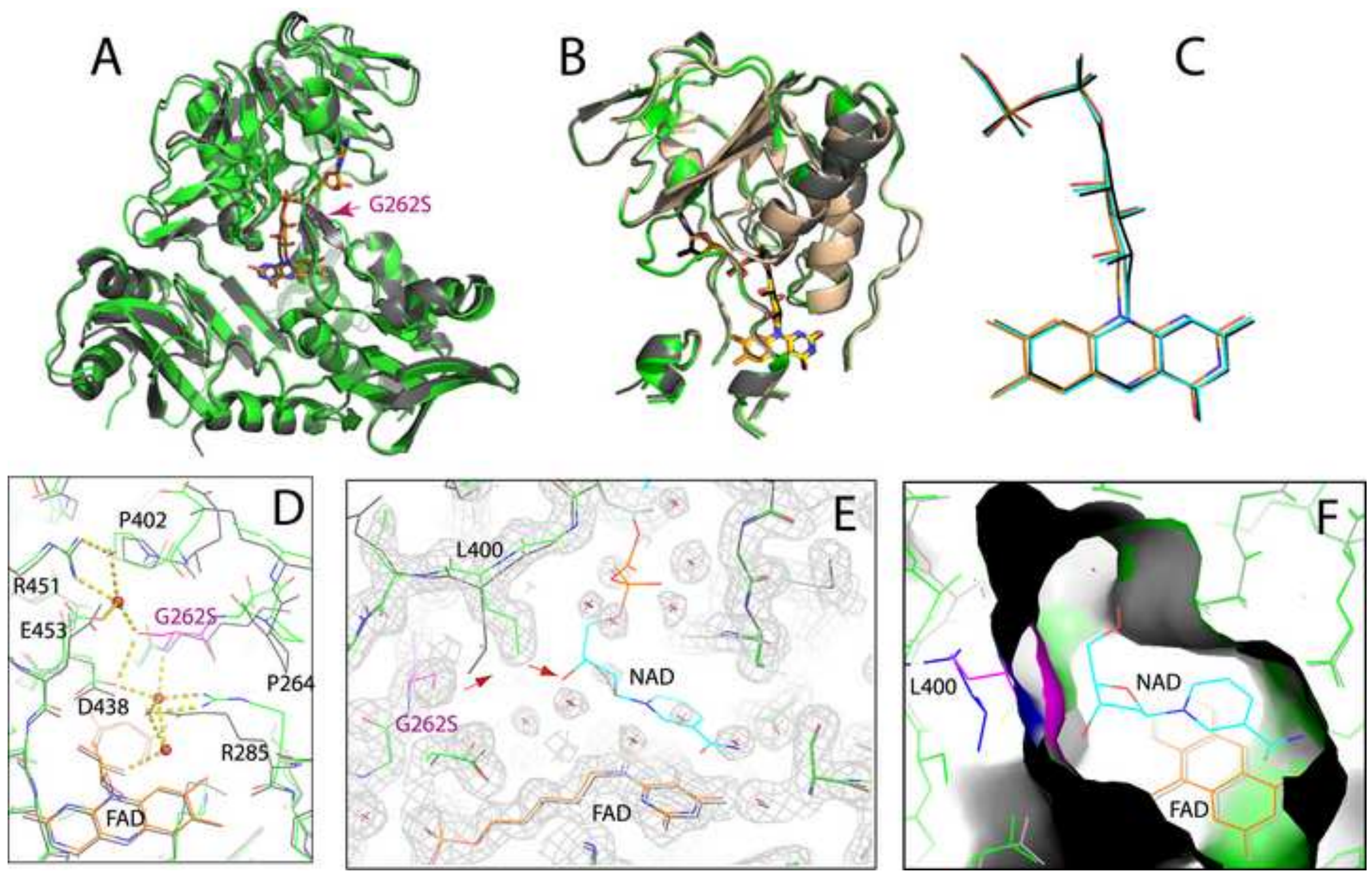